\title{
The present status and key problems of carbon nanotube based polymer composites
}

\author{
J-H. Du1 ${ }^{1}, J . B a i^{2}, H-M$. Cheng ${ }^{*}$ \\ ${ }^{1}$ Shenyang National Laboratory for Materials Science, Institute of Metal Research, Chinese Academy of Sciences, 72 \\ Wenhua Road, Shenyang 110016, P.R. China \\ ${ }^{2}$ Lab. MSS/MAT, CNRS UMR 8579, Ecole Centrale Paris, 92295 Châtenay Malabry CEDEX, France
}

Received 5 February 2007; accepted in revised form 6 April 2007

\begin{abstract}
The state-of-art and key problems of carbon nanotube (CNT) based polymer composites (CNT/polymer composites) including CNT/polymer structural composites and CNT/polymer functional composites are reviewed. Based on the results reported up to now, CNTs can be an effective reinforcement for polymer matrices, and the tensile strength and elastic modulus of CNT/polymer composites can reach as high as $3600 \mathrm{MPa}$ and $80 \mathrm{GPa}$, respectively. CNT/polymer composites are also promising functional composite materials with improved electrical and thermal conductivity, etc. Due to their multi-functional properties, CNT/polymer composites are expected to be used as low weight structural materials, optical devices, thermal interface materials, electric components, electromagnetic absorption materials, etc. However, the full potential of CNT/polymer composites still remains to be realized. A few key problems, such as how to prepare structurecontrollable CNTs with high purity and consistently dependable high performance, how to break up entangled or bundled CNTs and then uniformly disperse and align them within a polymer matrix, how to improve the load transfer from matrix to CNT reinforcement, etc, still exist and need to be solved in order to realize the wide applications of these advanced composites.
\end{abstract}

Keywords: polymer composites, carbon nanotubes, mechanical properties, electrical properties, thermal properties

\section{Introduction}

Since Iijima's report on CNTs in 1991 [1], scientists have been attracted by CNT's unique atomic structure and properties, such as high aspect ratio, high strength-to-weight ratio, extraordinary mechanical properties (their axial elastic modulus and tensile strength were theoretically predicted to be as high as 1-2 TPa and 200 GPa [2-6], respectively), superior thermal and electrical properties (thermally stable up to $2800^{\circ} \mathrm{C}$ in a vacuum or inert atmosphere, thermal conductivity about twice as high as diamond [7], and electric-current-carrying capacity 1000 times higher than copper wires [8]). These properties of CNTs endow themselves with new scientific and technological opportunities as an ideal filler material in composites. To date, various composite materials have been prepared by incorporating SWNTs or MWNTs into a metal matrix [9-12], a ceramic matrix [13-16] or a polymer matrix [17-33]. Polymers can be easily processed and fabricated into intricately shaped components without damaging CNTs during processing using conventional methods, and hence the manufacturing cost can be certainly reduced. Therefore, CNT based polymer composites (CNT/polymer composites) stimulate great interests and have been extensively investigated.

According to the different application purposes, $\mathrm{CNT} /$ polymer composites can be classified as structural composites and functional composites,

*Corresponding author, e-mail: cheng@imr.ac.cn

(C) BME-PT and GTE 
respectively. CNTs play a different role in the two kinds of composites. For CNT/polymer structural composites, the unique mechanical properties of CNTs, such as the high elastic modulus, tensile strength and strain to fracture, the ability to withstand cross-sectional and twisting distortions and compression without fracture, are generally explored to obtain structural materials with lightweight, high elastic modulus, high tensile and compressive strength and stiffness, etc. While for CNT/polymer functional composites, many other interesting properties of CNTs, such as the high electrical and thermal conductivity, are used to develop functional materials possessing heat resistance, chemical sensing, electrical conducting, thermal conducting, photoemission, electromagnetic absorbing or energy storage performances, etc.

In recent years, many polymers, such as epoxy [17-19], PMMA [20-22], PVA [23], PVC [24, 25], PP [26-28], PE [29, 30], PA12 [31], and PS [32, 33 ], have been employed as matrices to prepare CNT/polymer composites. The mechanical properties combining with electrical, thermal, optical and many other properties have been extensively investigated by many research groups for a wide range of applications. However, the reported results about these properties are scattered and still far from satisfactory. Analyses of these research results show that the performance of these composites depends on many factors, such as the types of CNTs (SWNTs or MWNTs) and their morphology and structure (diameter, length and chirality, for example) [34], the processing method, the choice of matrix [34, 35], the CNT dispersion within matrix [36], the interfacial interaction between CNTs and matrix, and so on.

In this article, we will present a comprehensive review about the preparation and processing, the properties and application of CNT/polymer composites. Some fundamental challenges, which have to be overcome in order to enable the wide applications of these advanced composites, are discussed.

\section{Preparation of CNT/polymer composites}

In the published reports, the common fabricating methods of CNT/polymer composites are solution mixing, melt blending and in situ polymerization. In solution mixing, CNTs are generally dispersed in solvent and then mixed with polymer solution by mechanical mixing, magnetic agitation or high- energy sonication. Subsequently, the CNT/polymer composites can be obtained by vaporizing the solvent at a certain temperature. This method is considered as an effective measure to prepare composites with a homogenous CNT distribution and often used to prepare composite films. Epoxy is a kind of thermosetting resins and is usually employed in CNT/epoxy composites by solution mixing. Many researchers, such as Xu et al. [37] and Lau et al. [38], have fabricated the CNT/epoxy composite using this method and reported their properties. Beside the epoxy resin, other polymers such as PS, PVA, PMMA and PVC can also be processed into $\mathrm{CNT} /$ polymer composites by solution mixing. Mamedov et al. [39] applied a new deposition technique called LBL assembly to make SWNT/polyelectrolyte multilayer composites, which can be considered as an improved solution mixing method. The resulting SWNT/polyelectrolyte membranes were very strong and the ultimate tensile strength was found to be $220 \pm 40 \mathrm{MPa}$ with some readings as high as $325 \mathrm{MPa}$.

Melt blending is a versatile and commonly used method to fabricate polymeric materials, especially for thermoplastic polymers. CNTs are dispersed within the polymer matrix by rheological shear stress generated from the blending of CNTs with melt polymer. Its well-known disadvantage is that CNTs can easily be damaged to a certain extent or broken in some cases [40, 41]. All the CNT/polymer composites using thermoplastic polymers as matrix can be processed in this manner. Jin et al. [42] fabricated MWNT/PMMA composite using this method and studied its dynamic mechanical behavior. The results indicate that CNTs were well dispersed in the polymer matrix with no apparent damage or breakage. The storage modulus of the polymer was significantly increased by the incorporation of CNTs particularly at high temperatures. The melt blending method is frequently used to prepare CNT/polymer composite fibers. Haggenmuller et al. [22] and Kumar et al. [26] prepared SWNT/PMMA composite fibers and CNF/PP composite fibers using melt spinning process and the obtained fibers showed improved mechanical properties.

In situ polymerization is considered as a very efficient method to significantly improve the CNT dispersion and the interaction between CNTs and polymer matrix. Generally, CNTs are firstly mixed with monomers and then $\mathrm{CNT} /$ polymer composites 
can be obtained by polymerizing the monomers under certain conditions. Jia et al. [20] initially reported the fabrication of CNT/PMMA composites by in situ polymerization. The results showed that a strong binding interface was formed between the CNTs and PMMA because the CNTs could be initiated by AIBN to open their $\pi$ bonds and participate in the PMMA polymerization. It was reported that for a surface modified CNT/PMMA composite fabricated by an improved in situ process, not only was the dispersion ratio of CNTs in the PMMA matrix improved, but also the mechanical properties of the composites were enhanced when the CNT content was lower than $10 \mathrm{wt} \%$. Ying et al. prepared surfactant-coated CNT/epoxy composites by in situ polymerizing epoxy resin with polyamide curing agent, and then their mechanical properties were studied [43-45]. The results showed that the tensile strength and ultimate strain of the composites were increased by $20 \%$ and $70 \%$, respectively. Li et al. [46] reported the fabrication and characterization of SWNT/PANI composites by in situ polymerization of an aniline solution containing different SWNT contents. Electron microscopy and conductive analysis showed that they had uniform CNT dispersion and high electric conductivity.

In order to bring out the anisotropic nature of CNTs, it is important to align CNTs in a polymer matrix during processing of CNT/polymer composites. This has been done by several groups [47-57] based on slicing the composite [51], mechanical stretching $[52,53]$, filtrating the CNT dispersion under a high magnetic field [54], melt-processing and electrospinning [55], etc. Gao et al. [56] described that aligned conducting CNTs can be used to make novel CP-NT coaxial nanowires by electrochemically depositing a concentric layer of an appropriate conducting polymer uniformly onto each of the constituent aligned CNTs. For a conducting-polymer sheathed CNT with an outer diameter of $221 \mathrm{~nm}$, inner diameter of $94.7 \mathrm{~nm}$ and length $9.3 \mu \mathrm{m}$, its elastic modulus was determined to be $13.6 \mathrm{GPa}$, much higher than that of the polymer. Li et al. [24] first reported to successfully synthesize long ropes of SWNT bundles with rope lengths up to $30 \mathrm{~mm}$. These ropes consist of roughly aligned SWNT bundles, which consist of wellaligned SWNTs. Then such aligned SWNT ropes were impregnated with PVC resin to form composite ropes. These ropes showed significantly improved mechanical properties with the average tensile strength as high as $3.6 \mathrm{GPa}$. Dalton et al. [25] used a modified coagulation-based CNT spinning method to spin a reel of nanotube gel fiber and then convert it into $100 \mathrm{~m}$ long solid CNT composite fiber in a continuous process, at a rate of more than $70 \mathrm{~cm} \cdot \mathrm{min}^{-1}$. The obtained composite fibers were about $50 \mu \mathrm{m}$ in diameter and contained around $60 \mathrm{wt} \%$ SWNTs. They had a tensile strength of $1.8 \mathrm{GPa}$ and tougher than most natural or synthetic organic fibers described so far.

\section{Present status of CNT/polymer composites}

\subsection{CNT/polymer structural composites}

CNTs are considered to be the ultimate mechanical filler material [58] and open the way for a new generation of high performance structural composites. In recent years, many studies with different focuses on mechanical properties of CNT/polymer structural composites have been published. However, the most impressive themes seem to be enhancement of elastic modulus and tensile strength. Another important property-fracture toughness has also been reported to be significantly improved in many works. We therefore will focus on the elastic modulus, tensile strength and toughness enhancement below.

Table 1 and 2 show some representative mechanical properties of randomly oriented and aligned $\mathrm{CNT} /$ polymer composites, respectively. From these two tables, it can be found that the elastic modulus of CNT/polymer composites can always be obviously increased comparing with those of pure polymer matrices. However, most of randomly oriented CNT/polymer composites show only a moderate or no strength enhancement, especially for CNT/polymer composites using untreated CNTs as reinforcements, mainly attributed to poor CNT dispersion within the matrix and poor load transfer between CNTs and polymer matrix. Homogeneous dispersion of CNTs throughout a matrix without destroying their integrity is essential for CNT reinforced polymer composites. Moreover, good interfacial bonding is required to achieve effective load transfer across CNT/matrix interface, a necessary condition for improving the mechanical properties of polymer composites [59-64]. From Table 1, it can be seen that the strength of nearly all CNT/polymer composites using modified CNTs as reinforce- 
Table 1. Representative mechanical properties of randomly oriented CNT/polymer composites

\begin{tabular}{|c|c|c|c|c|}
\hline Author & Sample & \begin{tabular}{|c|}
$\begin{array}{c}\text { Tensile strength } \\
{[\mathrm{MPa}]}\end{array}$ \\
\end{tabular} & \begin{tabular}{|c|}
$\begin{array}{c}\text { Elastic modulus } \\
{[\mathrm{GPa}]}\end{array}$ \\
\end{tabular} & Remarks \\
\hline Gong et al. [65] & Epoxy+1wt\% MWNTs & & $\begin{array}{l}\text { Increased by } \\
\text { more than } 30 \%\end{array}$ & \\
\hline \multirow{5}{*}{ Ying et al. [44] } & Pure Epoxy & 52 & 1.18 & \\
\hline & Epoxy + 2wt $\%$ MWNTs & 46 & 1.18 & Untreated MWNTs \\
\hline & Epoxy $+2 w t \%$ MWNTs & 55 & 1.35 & MWNTs were treated with PVA \\
\hline & Epoxy $+2 w t \%$ MWNTs & 62 & 1.39 & $\begin{array}{l}\text { MWNTs were treated with poly- } \\
\text { oxyethylene-9-alkyl ether }\end{array}$ \\
\hline & Epoxy $+2 w t \%$ MWNTs & 58 & 1.34 & $\begin{array}{l}\text { MWNTs were treated with poly- } \\
\text { oxyethylene-7-alkyl ether }\end{array}$ \\
\hline \multirow{3}{*}{ Andrews et al. [66] } & PS + 0.05 to 0.5 vol. $\%$ MWNTs & $\begin{array}{l}\text { Significant } \\
\text { reduction }\end{array}$ & Little change & \multirow{3}{*}{$\begin{array}{l}\text { MWNTs were heated in an inert } \\
\text { atmosphere to a high temperature } \\
\text { in the range } 1800 \text { to } 2600^{\circ} \mathrm{C}\end{array}$} \\
\hline & PS + 2.5 to 25 vol. $\%$ MWNTs & & $1.9 \sim 4.5$ & \\
\hline & $\begin{array}{l}\text { High impact PS \& ABS + } \\
0.05 \text { to } 0.5 \text { vol. } \% \text { MWNTs }\end{array}$ & $\begin{array}{l}\text { Little effect on } \\
\text { tensile strength } \\
\text { of either }\end{array}$ & Small increase & \\
\hline \multirow{3}{*}{ Zhang et al. [67] } & HDPE + $2 \mathrm{wt} \%$ SDS & $\sim 14.5$ & $\sim 0.47$ & \multirow{3}{*}{$\begin{array}{l}\text { SWNT aqueous solution prepared } \\
\text { at the aid of SDS was sprayed onto } \\
\text { the surface of HDPE. The compos- } \\
\text { ites were obtained by melt process- } \\
\text { ing }\end{array}$} \\
\hline & $\mathrm{HDPE}+2 \mathrm{wt} \% \mathrm{SDS}+0.5 \mathrm{wt} \% \mathrm{SWNT}$ & $\sim 19$ & $\sim 0.57$ & \\
\hline & $\mathrm{HDPE}+2 \mathrm{wt} \% \mathrm{SDS}+2.6 \mathrm{wt} \% \mathrm{SWNT}$ & $\sim 23$ & $\sim 0.7$ & \\
\hline \multirow{3}{*}{ Qian et al. [68] } & PS & $\sim 12.8$ & $\sim 1.19$ & \\
\hline & $\mathrm{PS}+1 \mathrm{wt} \%$ MWNTs & $\sim 16$ & $\sim 1.62$ & CNT with $15 \mu \mathrm{m}$ average length \\
\hline & $\mathrm{PS}+1 \mathrm{wt} \%$ MWNTs & $\sim 16$ & $\sim 1.69$ & CNT with $50 \mu \mathrm{m}$ average length \\
\hline \multirow{6}{*}{ Jia et al. [20] } & PMMA + $0.08 \mathrm{wt} \%$ AIBN & 54.9 & & \\
\hline & PMMA + $0.24 \mathrm{wt} \%$ AIBN + $1 \mathrm{wt} \%$ CNTs & 21.2 & & \multirow{2}{*}{ Untreated CNTs } \\
\hline & PMMA + $0.28 w t \%$ AIBN + $3 w t \%$ CNTs & 20.3 & & \\
\hline & PMMA + $0.1 \mathrm{wt} \%$ AIBN + $1 \mathrm{wt} \%$ CNTs & 58.7 & & \multirow{3}{*}{$\begin{array}{l}\text { CNTs were ground in a ball mill and } \\
\text { the improved in situ process was } \\
\text { used to fabricate the composites }\end{array}$} \\
\hline & PMMA + $0.1 w t \%$ AIBN + $3 w t \%$ CNTs & 66.8 & & \\
\hline & PMMA + $0.1 \mathrm{wt} \%$ AIBN + $5 \mathrm{wt} \%$ CNTs & 71.7 & & \\
\hline Jin et al. [42] & PMMA + MWNTs & \multicolumn{3}{|c|}{$\begin{array}{l}\text { The storage modulus was significantly increased, particularly at high } \\
\text { temperature }\end{array}$} \\
\hline Jin et al. [69] & PMMA + MWNTs & \multicolumn{3}{|c|}{$\begin{array}{l}\text { The storage modulus of composite containing } 0.5 \mathrm{wt} \% \text { PVDF was } \\
\text { almost twice as that of MWNT/PMMA without PVDF at } 50^{\circ} \mathrm{C}\end{array}$} \\
\hline \multirow{2}{*}{ Geng et al. [70] } & PEO & & 0.06 & \\
\hline & PEO + $1 \mathrm{wt} \%$ fluorinated SWNTs & & 0.15 & \\
\hline \multirow[b]{3}{*}{ Tong et al.[29] } & Pure PE & 34.1 & 0.81 & \\
\hline & $\mathrm{PE}+0.5 \mathrm{wt} \%$ SWNTs & 28.9 & 0.64 & Untreated SWNTs \\
\hline & $\mathrm{PE}+0.5 \mathrm{wt} \%$ SWNTs & 33.3 & 0.8 & $\begin{array}{l}\text { SWNTs were modified with PE } \\
\text { prepared by in situ Ziegler-Natta } \\
\text { polymerization }\end{array}$ \\
\hline \multirow{4}{*}{ Paiva et al. [71] } & PVA & & $\sim 4$ & \multirow{3}{*}{$\begin{array}{l}\text { CNTs were functionalized with low } \\
\text { molecular weight PVA }\end{array}$} \\
\hline & PVA + $2.5 \mathrm{wt} \%$ SWNTs & & $\sim 5.6$ & \\
\hline & PVA + 5 wt $\%$ SWNTs & & $\sim 6.2$ & \\
\hline & PVA + $2.5 \mathrm{wt} \%$ SWNTs & & $\sim 5.4$ & Untreated SWNTs \\
\hline
\end{tabular}

ments can be increased to some extent. It means that the surface modification of CNTs plays an important role in improving the mechanical reinforcement of the composites.

Compared to randomly oriented CNT/polymer composites, aligned configuration has a higher efficiency of reinforcement. In most cases, both tensile strength and elastic modulus of aligned CNT/polymer composites are significantly improved. In Fig- ure 1, the tensile strength (Figure 1a) and elastic modulus (Figure 1b) of randomly oriented and aligned CNT/polymer composites are summarized. It can be seen that the tensile strength and elastic modulus of randomly oriented CNT/polymer composites are generally less than $100 \mathrm{MPa}$ and $6 \mathrm{GPa}$, respectively. They are much lower than those of aligned CNT/polymer composites, which can even reach as high as $3600 \mathrm{MPa}$ and $80 \mathrm{GPa}$, respec- 
Table 2. Representative mechanical properties of aligned CNT/polymer composites

\begin{tabular}{|c|c|c|c|c|}
\hline Author & Sample & \begin{tabular}{|c} 
Tensile strength \\
{$[\mathrm{MPa}]$}
\end{tabular} & \begin{tabular}{|c|} 
Elastic modulus \\
{$[\mathrm{GPa}]$}
\end{tabular} & Remarks \\
\hline Gao et al. [56] & PANI + MWNTs & & 13.6 & $\begin{array}{l}\text { Prepared by electrochemical } \\
\text { deposition }\end{array}$ \\
\hline \multirow{3}{*}{ Andrew et al. [48] } & Isotropic petroleum pitch macrofiber & $\sim 450$ & $\sim 33$ & \multirow{3}{*}{$\begin{array}{l}\text { Produced by extrusion. The } \\
\text { average diameter of fibers was } \\
\sim 18 \mu \mathrm{m}\end{array}$} \\
\hline & $\begin{array}{l}\text { Isotropic petroleum pitch }+1 \% \mathrm{SWNT} \\
\text { macrofiber }\end{array}$ & $\sim 620$ & $\sim 42$ & \\
\hline & $\begin{array}{l}\text { Isotropic petroleum pitch }+5 \% \text { SWNT } \\
\text { macrofiber }\end{array}$ & $\sim 850$ & $\sim 78$ & \\
\hline \multirow{3}{*}{ Haggenmuelle et al. [22] } & Pure PMMA fiber & & $\sim 3.1$ & \multirow{3}{*}{$\begin{array}{l}\text { Produced by the melt spinning } \\
\text { process }\end{array}$} \\
\hline & $\begin{array}{l}\text { PMMA + } 1 \text { wt } \% \text { SWNT nanocomposite } \\
\text { fiber }\end{array}$ & & $\sim 3.3$ & \\
\hline & $\begin{array}{l}\text { PMMA + } 5 \text { wt } \% \text { SWNT nanocomposite } \\
\text { fiber }\end{array}$ & & $\sim 5$ & \\
\hline \multirow{2}{*}{ Kumar et al. [26] } & PP macrofiber & 490 & 4.6 & \multirow{2}{*}{$\begin{array}{l}\text { Spun using conventional melt } \\
\text { spinning technique }\end{array}$} \\
\hline & PP + 5 wt $\%$ MWNT macrofiber & 570 & 7.1 & \\
\hline \multirow{2}{*}{ Bhattacharyya et al. [50] } & $\mathrm{PP}$ & 430 & 4.2 & \multirow{2}{*}{ Significant CNT aggregation } \\
\hline & $\mathrm{PP}+0.8 \mathrm{wt} \%$ SWNTs & 420 & 4 & \\
\hline Li et al. [24] & PVC + SWNTs & 3600 & & \\
\hline Vigolo et al. [49] & PVA + SWNT composite fibers & & $9 \sim 15$ & \\
\hline Dalton et al. [25] & PVA + $60 \mathrm{wt} \%$ SWNT composite fiber & 1800 & 80 & $\begin{array}{l}\text { Produced by modified coagula- } \\
\text { tion-based CNT spinning } \\
\text { method }\end{array}$ \\
\hline \multirow{4}{*}{ Siochi et al. [72] } & PI & 105 & 2.2 & \multirow{4}{*}{$\begin{array}{l}\text { SWNT alignment in the com- } \\
\text { posite fiber direction was } \\
\text { induced by shear force present } \\
\text { during the melt extrusion and } \\
\text { fiber drawing processes }\end{array}$} \\
\hline & PI + 0.1 wt $\%$ SWNTs & 105 & 2.6 & \\
\hline & $\mathrm{PI}+0.3 \mathrm{wt} \%$ SWNTs & 105 & 2.8 & \\
\hline & PI + $1 \mathrm{wt} \%$ SWNTs & 105 & 3.2 & \\
\hline \multirow{2}{*}{ Chen and Tao [73] } & TPU & $\sim 12.4$ & $\sim 7.7$ & \multirow{2}{*}{ Prepared by a solution process } \\
\hline & TPU + 0.5 wt $\%$ SWNTs & $\sim 13.3$ & $\sim 14.5$ & \\
\hline \multirow{2}{*}{ Ruan et al. [74] } & UHMWPE & $\sim 3510$ & $\sim 122.6$ & \multirow{2}{*}{$\begin{array}{l}\text { Gel-spun composite fibers were } \\
\text { drawn at draw ratio of } 30\end{array}$} \\
\hline & UHWMPE + $5 \mathrm{wt} \%$ MWNTs & $\sim 4170$ & $\sim 136.8$ & \\
\hline
\end{tabular}

tively. Moreover, the tensile strength and elastic modulus are always higher for aligned CNT/polymer composites containing higher CNT content, while this is not the case for randomly oriented CNT/polymer composites.

In many reports, a critical CNT content in matrix can be found when the CNT strengthening effect on randomly oriented $\mathrm{CNT}$ /polymer composites are investigated. Below this content, the strengthening effect for randomly oriented $\mathrm{CNT} /$ polymer composites increases with increasing CNT content. Above this content, the strength of CNT/polymer composites decreases, and in some cases, even lower than that of the polymer matrix. The work of Bai et al. [34] shows that the critical CNT loading percentage was about $0.5 \mathrm{wt} \%$ for CNT/epoxy composites. This ratio is also very close to the percolation threshold for electrical conductivity. The same tendency was reported by Meguid and Sun [75] in their work on the tensile and shear strength of nano-reinforced composite interfaces. The excess CNTs increase the viscosity of polymers, and can also cause some surface of the CNTs not be completely covered by polymer matrix due to the large specific surface area of CNTs. This makes uniform dispersion and load transfer more difficult. Moreover, it is very difficult for high quantity of polymers to intercalate among CNTs when the CNT content becomes high. Shaffer et al. [76] reported that, by trivial estimation, even a 1 vol\% loading of SWNTs ensures that all of the polymer molecules are within one radius of gyration (say $5 \mathrm{~nm}$ ) of a nanotube. This result implies that complete wetting of high loading fraction of SWNTs will be difficult, at least by conventional means.

Although much higher than those of randomly oriented CNT/polymer composites and, in some cases, representing the highest mechanical properties amongst all ultra-strong fibers reported so far, the obtained tensile strength and elastic modulus of aligned CNT/polymer composites are still far from satisfactory as far as the mechanical properties of 

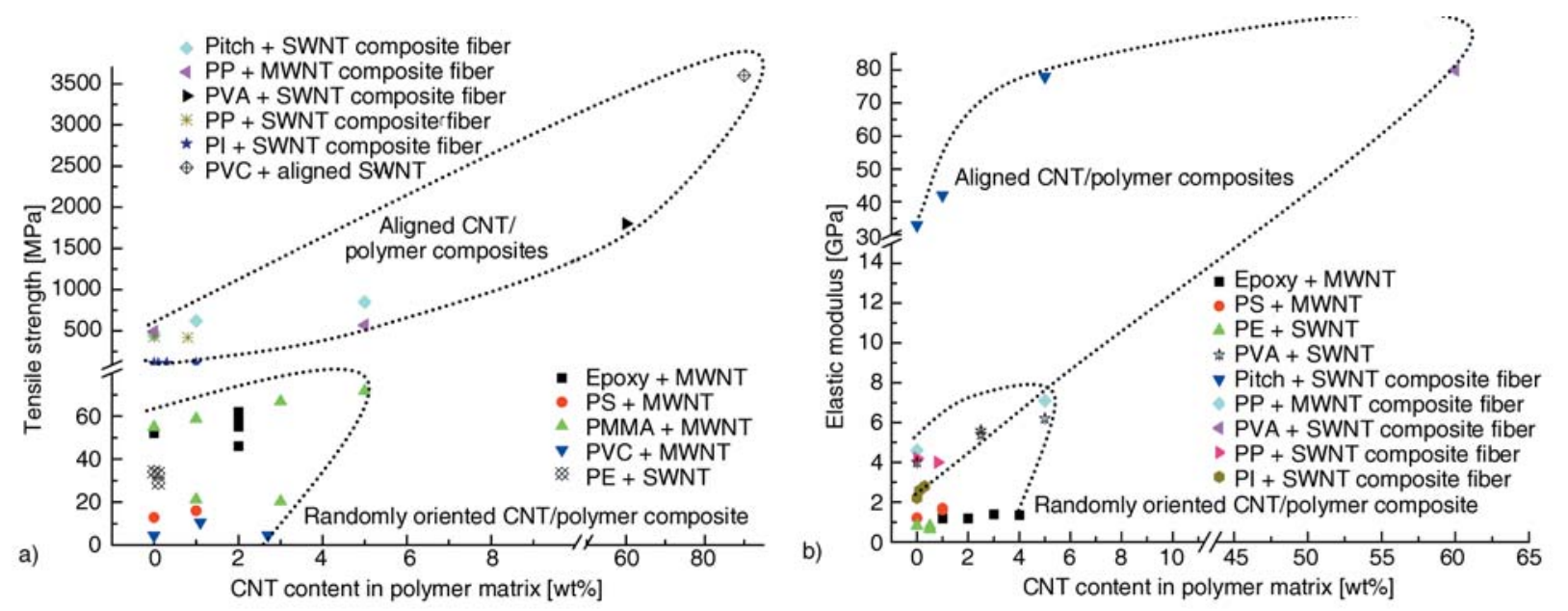

Figure 1. Tensile strength (a) and elastic modulus (b) of CNT/polymer composites

CNTs are considered. The main possible reason is sliding between CNTs under macroscopic tensile loading and between CNT and matrix.

Figure 2 shows several representative stress-strain curves of CNT/polymer composites with different polymers as matrices. It can be found that the curvilinear trend of CNT/polymer composites strongly depends on the matrix nature. Most of the reported

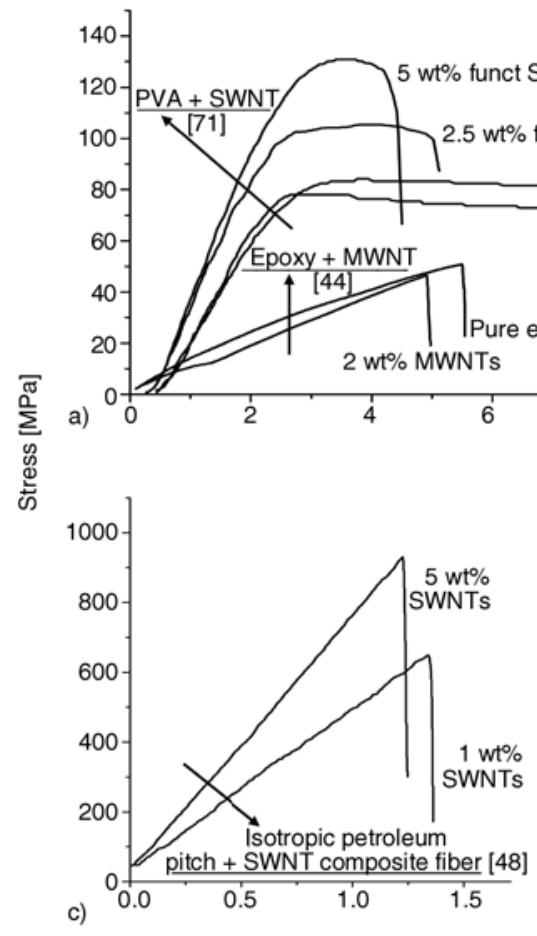

stress-strain curves show improvement in strength and loss of strain to failure (Figure 2a, c, d). The strain to failure usually decreases with the increase of CNT content. However, CNT/polymer composites using PE and PEO as matrices show a substantial enhancement in strain to failure and toughness (Figure 2b). This indicates that significant toughening of some polymer matrices through the incorpo-
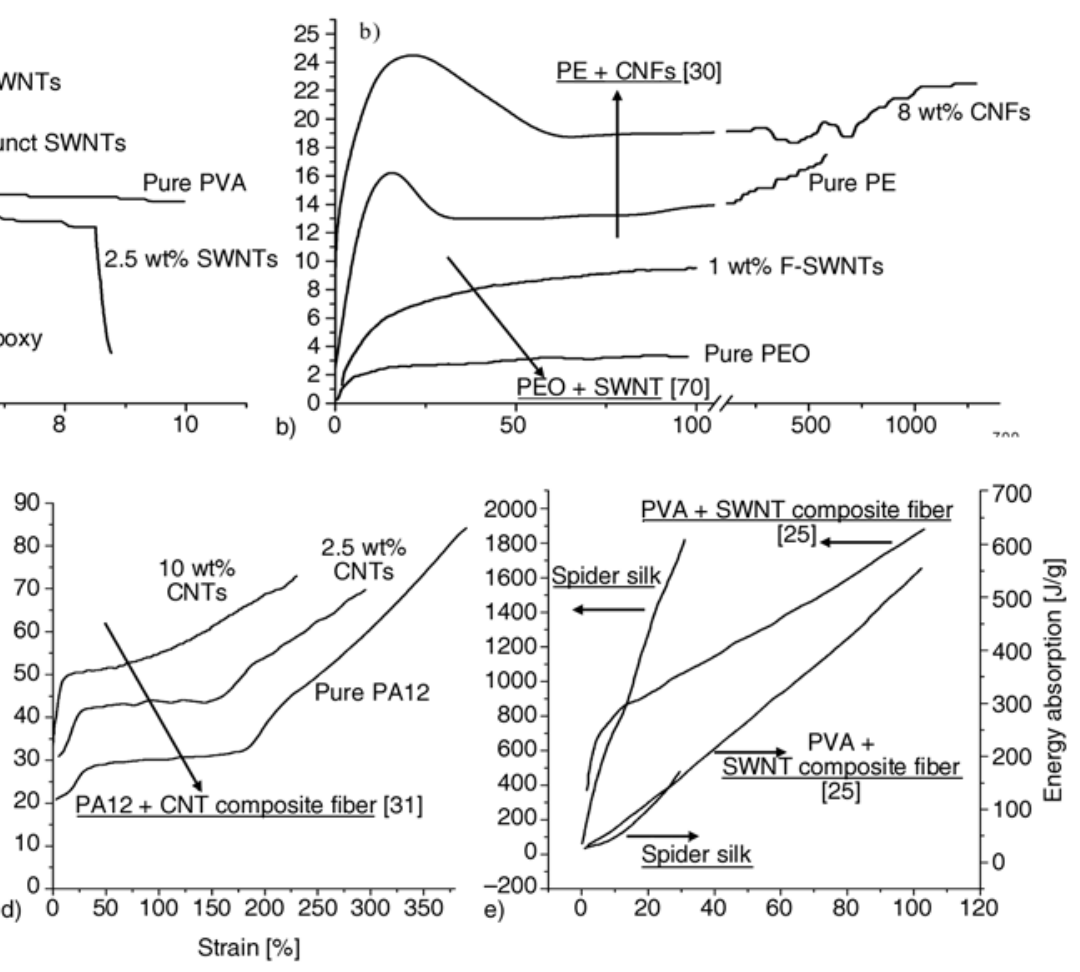

Figure 2. Representative strain-stress curves of CNT/polymer composites using different polymers as matrix. a, b) randomly oriented CNT/polymer composites [30, 44, 70, 71] and c, d, e) aligned CNT/polymer composites [25, 31, 48]

[25] Reused with permission from NPG

$[30,31,71]$ Reused with permission from Elsevier

[48] Reused with permission from American Institute of Physics

[70] Reused with permission from Wiley-VCH 
ration of CNTs can be obtained. In such instances, the commonly used polymers including PE, PEO and PVA, are semi-crystalline thermoplastic polymers. Certain conditions, such as the presence of modified CNTs, preparation temperature of composites, pre-drawing treatment of CNT/polymer composite fibers at the temperature above the $T_{g}$ of polymer matrix generally can influence their crystallization behaviour, and hence significantly affect the toughness characteristics of the composites. Ruan et al. [77] first reported that MWNT/PE composite films with high pre-drawing ratios showed an up to $150 \%$ increase in strain energy density together with a simultaneous increase of tensile strength of $\sim 25 \%$ and an increase of ductility up to $140 \%$ in comparison with the pure PE film at similar pre-drawing ratio. Secondary crystallites, which were nucleated from the MWNTs and might grow during hot drawing, were much more mobile than the extended PE crystals and led to a significantly enhanced ductility and hence an increase in strain energy of the composite film [78]. Lozano et al. [30] reported that CNFs, which can also be considered as MWNTs since the diameter of fibers ranging between 40 and $150 \mathrm{~nm}$, and PE could act in a synergistic manner to increase both strength and strain to failure of $\mathrm{CNF} /$ polymer composites (Figure $2 \mathrm{~b}$ ). They prepared the composite by mixing the functionalized CNFs and $\mathrm{PE}$ at $180^{\circ} \mathrm{C}$ and then pressed at $200^{\circ} \mathrm{C}$. Dalton et al. [25] reported that their pre-drawn $60 \mathrm{wt} \%$ SWNT/PVA composite fibers matched the energy absorption of spider silk up to the breaking strain of the toughest silk (30\%), and continued absorbing energy until reaching an energy-to-break $(570 \mathrm{~J} / \mathrm{g})$ which is much higher than that of spider dragline silk (165 J/g [79]) (Figure 2e). While SWNT/PVA composite film, which was prepared by wet-casting [71] and no pre-drawing treatment and crystallinity, shows no increase in toughness (Figure 2a).

Since CNTs can enable polymer matrix to obtain a stronger and more lightweight composite due to their superior mechanical properties and small size, the obvious application of CNT/polymer composite can be as structural materials in several fields including aerospace, sports, automotive, infrastructure and defense. For example, super strong CNT/ polymer composite fibers will have many applications including body and vehicle armor, transmission line cables, woven fabrics and textiles, etc. CNTs' high strength and toughness-to-weight char- acteristics may also prove valuable as part of composite components in fuel cells that are deployed in transport applications, where durability is extremely important. Inspired partly by science fiction, NASA scientists are seriously considering space elevators as a mass-transit system. The material of choice for a space elevator is a super-strong CNT/ polymer composite fiber, which is the only known substance at present that can successfully be used and make a space elevator possible. Several manufacturers of sports equipment have advertised CNTs as reinforcements of some of their top sports products. Easton Sports, the leading manufacturer of sporting goods, manufactured the world's first CNT two-piece all-composite bats, which represents the best bats Easton Sports has ever made [80].

\subsection{CNT/polymer functional composites}

\subsubsection{Electrical properties and application of CNT/polymer composites}

Many experimental results have shown that the combination of CNTs with polymers offers an attractive route to introduce new electrical properties [17, 23, 66, 81], and conductive composites can be constructed at low loading of CNTs due to low percolation thresholds originated from the high aspect ratio and conductivity of CNTs. Figure 3 and Table 3 summarize some reported electrical properties of $\mathrm{CNT} /$ polymer composites. It can be found in Figure 3 that all CNT/polymer composites exhibit a typical percolation behavior and introduction of CNTs to polymers can increase the conductivity of the resulting composites to several orders of magnitude or even higher than ten orders of magnitude. However, very different percolation thresholds (from $0.0025 \mathrm{wt} \%$ for CNT/epoxy composite to $11 \mathrm{wt} \%$ for SWNT/P3OT composite) have been obtained by different research groups (see Table 3). Sandler et al. [17] measured the electrical conductivity of untreated CNT/epoxy composites, and found that the percolation threshold was between 0.0225 and 0.04 wt\% CNTs. Subsequently, they further presented the lowest threshold (0.0025 wt \% for aligned SWNT/epoxy composites) observed for CNT/polymer composites yet reported [83]. Allaoui et al. [84] also studied the electrical performance of MWNT/epoxy composites and revealed that the presence of a percolation thresh- 


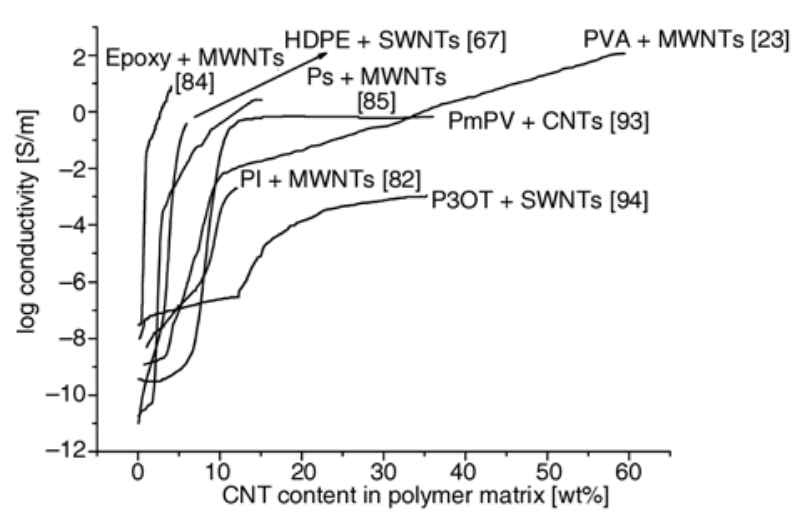

Figure 3. Representative semilogarithmic plot of the electrical conductivity of CNT/polymer composites with various weight percents of CNTs in different polymer matrices $[23,67,82,84,85,93$, 94].

[23] Reused with permission from Wiley-VCH $[67,82,84,94]$ Reused with permission from Elsevier

[85] Reused with permission from Springer [93] Reused with permission from

Dr. J. N. Coleman

old between 0.5 and $1 \mathrm{wt} \%$ CNTs. When adding $1 \mathrm{wt} \%$ CNTs into epoxy matrix, the composite became conductive with a conductivity as high as $10^{-3} \mathrm{~S} / \mathrm{cm}$. Shaffer et al. [23] fabricated CNT/PVA composites and measured their electrical conductivity using impedance spectroscopy in a four-point configuration. The percolation threshold for these composites lay between 5 and $10 \mathrm{wt} \%$. At the CNT concentration of $10 \mathrm{wt} \%$, the electrical conductivity of the composite was about $1 \mathrm{~S} / \mathrm{cm}$, an increase

Table 3. Representative percolation threshold of CNT/ polymer composites

\begin{tabular}{|c|c|c|}
\hline Author & Sample & $\begin{array}{c}\text { Percolation } \\
\text { threshold [wt\%] }\end{array}$ \\
\hline Sandler et al. [17] & Epoxy + CNTs & $0.0225 \sim 0.04$ \\
\hline Sandler et al. [83] & $\begin{array}{l}\text { Epoxy + aligned } \\
\text { MWNTs }\end{array}$ & 0.0025 \\
\hline Allaoui et al. [84] & Epoxy + CNTs & $0.5 \sim 1$ \\
\hline Shaffer et al. [23] & PVA + MWNTs & $5 \sim 10$ \\
\hline Dufresne et al. [85] & PS + MWNTs & $\leq 3$ \\
\hline Andrews et al. [66] & PS + MWNTs & 0.25 vol. $\%$ \\
\hline Barraza et al. [86] & PS + SWNTs & 8.5 \\
\hline Zhang et al. [67] & HDPE + SWNTs & 4 \\
\hline McNally et al. [87] & PE + MWNTs & 7.5 \\
\hline Hu et al. [88] & PET + MWNTs & 0.9 \\
\hline Seo et al. [89] & $\mathrm{PP}+\mathrm{CNTs}$ & $1 \sim 2$ \\
\hline Seo et al. [90] & $\mathrm{PP}+\mathrm{CNTs}$ & 2 \\
\hline Tchmutin et al. [91] & PP + SWNTs & 4.5 vol. $\%$ \\
\hline Meincke et al. [92] & PA6 + CNTs & $4 \sim 6$ \\
\hline Coleman et al. [93] & PmPV + CNTs & 8.5 \\
\hline Kymakis et al. [94] & P3OT + SWNTs & 11 \\
\hline
\end{tabular}

by about seven orders of magnitude. Kymakis et al. [94] presented a percolation threshold of approximately $11 \mathrm{wt} \%$ SWNTs in a P3OT polymer. As the CNT concentration increased from 0 to $20 \mathrm{wt} \%$, the conductivity of the composites was increased by five orders of magnitude.

Based on the reported results up to now, CNT/ epoxy composites show a much lower percolation threshold, although the reported values are very different. For CNT/PS composites, the percolation threshold was reported ranging from $0.25 \mathrm{vol} \%$ to $8.5 \mathrm{wt} \%$ by different groups. These differences can be attributed to many factors. The electrical properties of CNTs used by different research groups are generally significantly different depending on their purity, morphology, aspect ratio, etc. In addition, the interaction between matrix and CNTs influences the quality and quantity of electrical contacts between the CNTs. As reported by Shaffer et al. [23], it seems that the P3OT is easier to form an adsorbed layer on the surface of CNTs than epoxy resin, which reduces the quality and quantity of electrical contacts, thus the percolation threshold of CNT/P3OT composite cannot be reached at a relatively lower CNT loading. In Table 3 , it can also be found that the electrical percolation threshold of CNT/polymer composites with semicrystalline thermoplastic matrices (PP, PE, PEO, PA) is always higher than those of CNT/epoxy composites. Hu et al. [88] first used coagulation method to prepare MWNT/PET composites and found that the percolation threshold of the composite was $0.9 \mathrm{wt} \%$. Seo et al. $[89,90]$ presented that the conductivity of CNT/PP composites was increased with increasing the CNT content and the electrical percolation threshold was formed between 1 and $2 \mathrm{wt} \%$ CNTs. Meincke et al. reported that percolation threshold of CNT/PA6 composite at CNT loading 4 6 wt $\%$. Additional complexity arises in case of semi-crystalline matrices, where it is envisaged that the dispersion of CNT is significantly affected due to the crystallization induced phase separation and subsequent rejection of CNTs by the advancing crystalline fronts [95]. On the other hand, purity and defect concentration of CNTs, dispersion and alignment of CNTs within a matrix, are also the main factors influencing the electrical properties of CNT/polymer composites.

Nevertheless, compared with $\mathrm{CB}$ and carbon fiber based composites, whose electrical percolation threshold are usually up to $15-20 \mathrm{wt} \%$ and 9- 
$18 \mathrm{wt} \%$, respectively, CNT/polymer composites still have much lower electrical percolation threshold due to their high aspect ratio and small diameter. Therefore, in many fields, CNTs are expected to substitute $\mathrm{CB}$ as conductive fillers. In 2005, He et al. [96] reported the temperature-resistivity characteristics of MWNT/HDPE composites. They found that when temperature was between 120 and $130^{\circ} \mathrm{C}$, the electrical resistivity of the $5.4 \mathrm{wt} \%$ MWNT-filled HDPE composite increased sharply with the increase of temperature, showing a strong PTC effect. While for CB/HDPE composite, the loading concentration of $\mathrm{CB}$ was nearly three times as high as that of MWNTs to obtain the PTC effect. Moreover, when temperature was above $T_{m}$ of HDPE, the CB/HDPE composite exhibited obvious NTC effect. However, the NTC effect in MWNT/ HDPE composites was quite small. So, CNT instead of $\mathrm{CB}$ based polymer composites are expected to be used in self-controlled heaters, overcurrent protectors, sensors, etc.

Besides, given high conductivity and super mechanical properties of CNT/polymer composite, they can also be exploited as EMI shielding composites, coatings for enclosures, ESD composites, antistatic materials, conductive coatings, electromagnetic absorption materials for low-observable applications, electrode materials for supercapacitor and fuel cell, etc.

\subsubsection{Thermal properties and application of CNT/polymer composites}

Many researches indicate that CNTs may be the best heat-conducting material that has ever been known. Scientists predict that the thermal conductivity can reach as high as $6600 \mathrm{~W} / \mathrm{mK}$ at room temperature for a SWNT [97] and experimental value is $3000 \mathrm{~W} / \mathrm{mK}$ for an isolated MWNT at room temperature [98]. It is expected, therefore, that CNTs can significantly enhance the thermal conductivity and thermal stability of some polymers at high temperature [99-102]. Wei et al. [101] carried out classical molecular dynamics simulations employing Brenner potential for intra-nanotube interactions and van der Waals force for polymer-nanotube interface to investigate the thermal expansion and diffusion characteristics of CNT/PE composites. The addition of CNTs was found to increase $T_{g}$ and thermal expansion and diffusion coefficients in the composite above $T_{g}$. Xu et al. [103] fabricated SWNT/PVDF composites by dispersion of SWNTs in an aqueous surfactant solution, followed by mixing with PVDF powder, filtration and hot pressing. The measured thermal diffusivity of the composites increased with increase of the SWNT content, but decreased with increasing temperature because the phonon scattering was enhanced with increasing temperature for polymers. Kashiwagi et al. [99] fabricated MWNT/ PP composites with good dispersion, and CNTs were found to significantly enhance the thermal stability of PP in nitrogen at high temperatures. Especially, the CNT addition significantly reduced the heat release rate of PP and they were found to be at least as effective as clay/PP composite for flame-retardance.

Many efforts have also been devoted to the use of CNTs as thermal conducting fillers in polymer composites and some enhancements in the thermal conductivity are usually observed. Thostenson et al. [104] found that the thermal conductivity of CNT/epoxy composites increased linearly with CNT concentration to a maximum increase of $60 \%$ at $5 \mathrm{wt} \%$ CNTs. Liu et al. [105] reported an enhancement of $65 \%$ in thermal conductivity with $4 \mathrm{wt} \%$ CNT loading in silicone elastomer. Biercuk et al. [102] used SWNTs to augment the thermal transport properties of epoxy and found that epoxy loaded with $1 \mathrm{wt} \%$ SWNTs exhibited a $70 \%$ increase in thermal conductivity at $40 \mathrm{~K}$ and $125 \%$ at room temperature. But these enhanced values are still far below those predicted using the 'rule of mixtures' and unlike electrical conductivity, which is based on a percolation mechanism, the increase in thermal conductivity with increasing CNT concentration is nearly linear in many cases, while in practice this has been observed to be nonlinear in certain cases. The important reasons probably rest in lower intrinsic thermal conductivity of the CNTs used, scattering of phonons by interactions with the surroundings or with defects. An alternative or probably main reason is that high resistance at the CNT-matrix or CNT-CNT interfaces limits thermal transport along percolating networks of CNTs and this leads to a rapid increase in the overall thermal resistance.

In order to investigate the effect of interface thermal resistance at CNT-matrix, which may be due to the weak bonding between polymer matrix and CNT walls, many numerical simulations have been carried out to predict the interfacial heat flow 
between the CNTs and the matrix. Shenogin et al. [106] studied the effect of thermal boundary resistance on the heat flow in CNT composites. They found that the effective thermal conductivity of $\mathrm{CNT} /$ polymer composites was limited by interface resistance. A theoretical model was proposed by Huxtable et al. [107] to evaluate the thermal conductivity of the composite with interface resistance, and it was found that the interface played an important role in the thermal conduction through CNT composites. Nan et al. [108] developed a simple formula for the thermal conductivity enhancement in composites by incorporating the interface thermal resistance with an effective medium approach, and found that a large interface thermal resistance across the CNT-matrix interface caused a significant degradation in the thermal conductivity enhancement, even for the case with ultrahigh intrinsic thermal conductivity and aspect ratio of the CNTs embedded. On the other hand, the relationship between thermal conductivity and functionalization of the surface of CNTs are also be predicted by many groups because surface modification to CNTs is a possible approach to improve the interfacial adhesion and then reduce the interfacial thermal resistance between the CNTs and the matrix. However, many calculations indicate that the interface thermal resistance has a smaller effect on the overall conductivity of the composites, which is especially sensitive to the length and diameter of CNTs [109, 110]. Consequently, some experiments are designed to investigate the functionalized CNTs on the thermal conductivity of composites. Liu et al. [111] prepared the composites of the polydimethylsiloxane rubber with $2 \mathrm{wt} \%$ chemical-treated CNTs to investigate the influence of chemical modifications and defects on the thermal conductivity of CNT composites. This study reveals that moderate chemical modifications are beneficial to improve the thermal conductivity of CNT composites. However, their negative effects to the thermal conductance are more remarkable than the theoretical anticipation. Figure 4 shows the measured thermal conductivity of epoxy matrix composites with different fillers and content [112]. It can be seen that the largest improvement is nonfunctionalized CNT composites. These experimental results substantiate the requirement of a weak interfacial adhesion, since the composites containing amino-functionalized CNTs show relatively lower thermal conductivity compared to the corre-

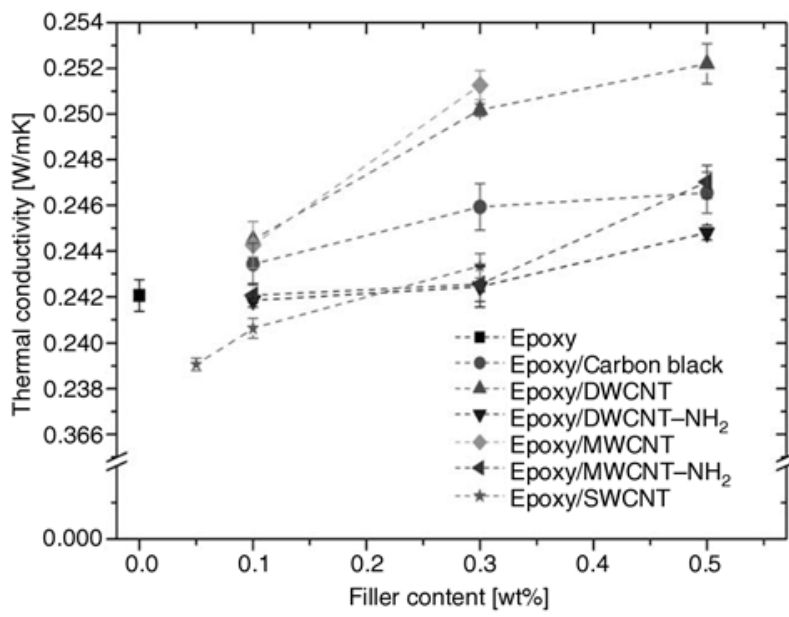

Figure 4. Thermal conductivity as a function of filler content for epoxy composites[112]. Reprinted with permission from elsevier

sponding composites with non-functionalized CNTs. Based on these theoretical and experimental results, it is obvious that to reduce interfacial thermal resistance by functionalization of CNTs is not preferable, and some new techniques therefore should be developed.

To avoid the effect of interface thermal resistance between the overlaps in CNT passage, an ideal CNT composite structure (TIM Model) was proposed by Huang et al. [113] to take advantage of the high thermal conductivity of CNTs. In their structure, all the CNTs embedded in the matrix were aligned from one surface to the opposite side with all the CNT tips revealed on both surfaces. According to this model, the aligned CNT composite film was prepared by in situ injection molding method. The enhanced thermal conductivity as a function of CNT loading for both aligned CNTs and randomly oriented CNTs are plotted in Figure 5. It can be seen that with only a small fraction of aligned CNTs $(0.3 \%)$, the enhanced value of thermal conductivity is fairly high $(0.65 \mathrm{~W} / \mathrm{mK})$. However, from the inset of Figure 5, it can be seen that there is only a marginal enhancement using the same loading of randomly oriented MWNTs, and the enhanced value is only $4.6 \%$ of that of an aligned CNT array. Obviously, the new structure is very effective to improve the thermal conductivity of CNT composites.

The prominent thermal properties of CNTs make them promising materials for future application as thermal management materials, such as TIMs, which are commonly used to fill air gaps between two surfaces of electronic components and base 


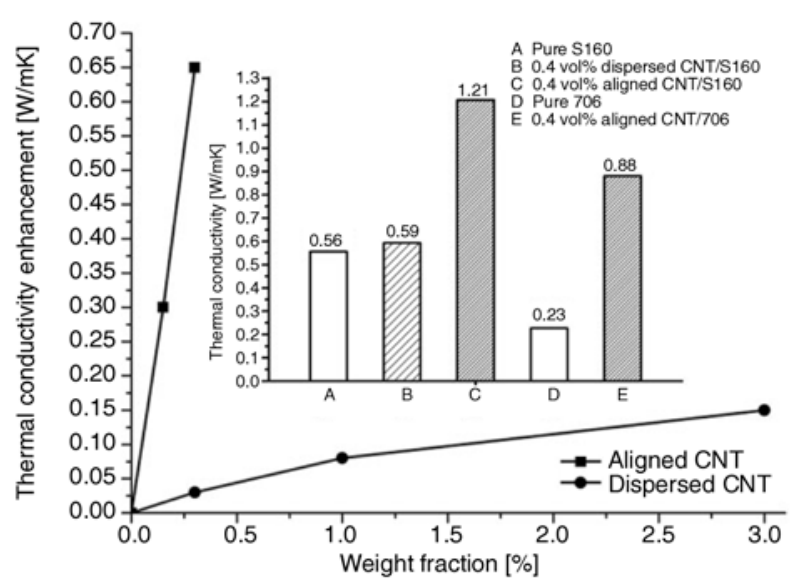

Figure 5. The enhanced values of thermal conductivity of CNT/polymer composites vs. weight fractions of CNTs [113]. Reprinted with permission from Wiley-VCH

plates of heat sinks, and thus minimize the thermal contact resistance between them and dissipate heat efficiently [114]. Based on the ideal TIM model Huang et al. [113] predicted that if the volume fraction of CNTs can be as high as $10 \%$ in the composites, the value of thermal conductivity would increase to an order of magnitude higher than that of most current commercial materials. They can also be used as temperature sensors, resistance heating and flame-retardance materials, etc.

\subsubsection{Other functional properties and application of CNT/polymer composites}

Beside electrical and thermal properties, optical and many other functional properties of CNT/polymer composites, are also fascinating. Jin et al. [115] studied the nonlinear optical properties of MWNT/PPA-C16TAB composite with $532 \mathrm{~nm}$ nanosecond laser pulses and obtained an effective nonlinear refractive index of $6.8 \cdot 10^{-18} \mathrm{~m}^{2} / \mathrm{W}$. Similarly, a value of $1.2 \cdot 10^{-17} \mathrm{~m}^{2} / \mathrm{W}$ was obtained for MWNT/PEO composite [116]. They predicted that MWNT/PPA-C16TAB composite could be a potential candidate for solid nonlinear optical devices because of its ease to prepare a cast film. Davey et al. [63] prepared MWNT and SWNT/ PmPV composites, and found that SWNTs could be used to enhance the luminescent properties of the conjugated polymer PmPV. The enhancement of luminescence and thus an increase in quantum yield opens up the area of luminescent polymers. Davey et al. [63] also proposed that the main contribution of CNTs to optical nonlinearity would arise from 1-D polarization of delocalised $\pi$-electrons in a fixed lattice configuration. They found that MWNT/PmPV composite showed a strong nonlinear signal, which is very applicable in the area of high performance nonlinear optical devices. Chen et al. [117] reported that SWNT/polymer composites, especially SWNT/PI composite, not only had an optical decay time of less than $1 \mathrm{ps}$, but also a high third-order nonlinear polarizability, which makes the composite a promising material for high-quality subpicosecond all-optical switches. A few papers have studied the electromagnetic and microwave absorption properties of polymer composites reinforced with CNTs. Fan et al. [118] studied electromagnetic and microwave absorption applications of CNT/PET, PP, PE and varnish composites in the range of $2-18 \mathrm{GHz}$, and found that $4 \mathrm{wt} \% \mathrm{CNT} / \mathrm{PET}$ and $8 \mathrm{wt} \%$ CNTs/varnish composites had considerable absorbing peak at 7.6 GHz, $15.3 \mathrm{GHz}$ and achieved maximum absorbing value of $17.61 \mathrm{~dB}, 24.27 \mathrm{~dB}$, respectively. In addition, the frequency ranges for absorbing values exceeding $5 \mathrm{~dB}$ of $\mathrm{CNT} /(\mathrm{PET}$, PP, varnish) composites are $13 \mathrm{GHz}, 10 \mathrm{GHz}$ and $6 \mathrm{GHz}$, respectively. The microwave absorption between $2 \mathrm{GHz}$ and $18 \mathrm{GHz}$ can be mainly attributed to the dielectric loss rather than magnetic loss. The results indicate that these composites are good candidates as microwave absorption materials.

Recently, Wei et al. [119] synthesized PANI nanotubes doped with MWNT- $\left(\mathrm{OSO}_{3} \mathrm{H}\right)_{n}$ through selfassembly method and Zhang et al. [120] developed a facile approach to noncovalently functionalize graphitized MWNTs with the water-soluble conducting polymer of SPAN. The functionalization was based on the in situ polymerization of aniline and MWNTs followed by sulfonation with chlorosulfonic acid in an inert solvent and by hydrolysis in water. The lengths and surface structure of MWNTs were not perturbed with the incorporation of SPAN. The SPAN functionalized MWNTs (MWNT/SPAN composite) were highly soluble in water. These reports open many new possibilities for the prospective technological applications of $\mathrm{CNT} /$ polymer composites in nanoelectronic and biomedical devices and sensoring, etc. In addition, the addition of CNTs to the polymer matrices can also modify the electromagnetic interference shielding effectiveness, optoelectronic properties [121], thermoelectric energy conversion, etc. 


\section{Key problems of CNT/polymer composites}

Based on the review about the properties and application of CNT/polymer structural composites and functional composites, it is obvious that CNT/polymer composites are muti-functional and are expected to be used as automotive components, sports goods, and electronic products. They also can be used in textile and aerospace industry, etc. In a word, the application of CNT/polymer composites is at an embryonic stage of development but the scope is large and growing. The present status demonstrates that the results of enhancement in performance of CNT/polymer composite are scattered, especially for CNT/polymer structural composites. Many key issues should be addressed to realize the wide applications of these advanced composites in practice.

\subsection{Structure control of CNTs}

It is well known that the most important factor that determines the ultimate mechanical and other functional properties of $\mathrm{CNT} /$ polymer composites should be the inherent properties of CNTs. Presently, a large amount of CNTs can be prepared by electric arc discharge, laser ablation and chemical vapor deposition. But the obtained CNTs are not consistent in their structure, morphology, aspect ratio, crystallinity, crystalline orientation, purity, electric conductivity and mechanical properties, etc. Therefore, the properties of resulting $\mathrm{CNT} /$ polymer composites will naturally be very different even if the composites are fabricated by the same method and with the same polymer matrix.

To obtain the CNTs of high purity and uniformity is one of the big issues that still impact the applications of CNT/polymer composites. The as-prepared CNTs are usually not pure and contain a lot of impurities, some of them, such as amorphous carbon and fullerenes, can hardly be completely removed from the raw materials, and the purity is difficult to be quantified. Thus, the measured physical and chemical properties of CNTs are peculiar to different research groups. In addition, the structures of the obtained CNTs always possess surface defects and even are not identical in geometrical structure, which cause the actual mechanical strength, electrical and thermal conductivity as well as other properties far from the theoretical predictions. Furthermore, CNTs are not continuous so that the macroscopic samples will not have the same good performance as the single CNT. Therefore, to start with, the most important problem is to prepare structure-controllable CNTs with high purity, geometrical uniformity and consistently dependable high performance.

In addition, CNTs normally are randomly oriented and entangled with each other. Especially, CNTs prepared by electric arc discharge tend to form bundles. It is very difficult to break up these entangled and bundled CNTs to produce individual ones and then disperse them uniformly in polymer matrices. Therefore, a revolutionary progress of CNT application can only be realized when we know how to break up the entangled and bundled as-prepared CNT products to produce individual CNTs without damaging their properties or to directly produce individual CNTs.

\subsection{Dispersion of CNTs within polymer matrix}

Uniform dispersion of CNTs in polymers is also a fundamental challenge. In fact, no matter what preparation method is adopted, the main purpose is to uniformly disperse CNTs within a polymer matrix and obtain composites with intrinsic properties [59, 60, 122]. In general, several factors that influence the dispersion of CNTs in a polymer matrix have to be considered in the preparation process of CNT/polymer composites. The entangling of CNTs during growth process and the attraction between CNTs by van der Waals force make CNTs themselves tend to aggregate. So it is difficult for CNTs to be separated from one another within the polymer matrix in mixing stage. These factors prevent CNTs from being well dispersed within polymers. The obtained CNT/polymer composites are poor in their mechanical performance and the intrinsic properties of the composites cannot be achieved.

Presently, there are two main kinds of surface treatment for CNTs to improve their dispersion within a polymer matrix. One is surface functionalization: Some functional groups, which can improve the interaction between CNTs and polymer matrix, are covalently bonded directly to the surface of CNTs. Gojny et al. [19] treated MWNTs with oxidizing inorganic acids. The oxidized CNTs were embed- 
ded in epoxy resin and the resulting composite was investigated by TEM. The results indicated that through the treatment with oxidizing inorganic acids, the outer shells of CNTs were damaged to some extent and carboxylic groups were formed on the surface, which enables a better dispersion of CNTs. However, surface functionalization may disrupt the bonding between graphene sheets, and thereby reduce the properties of functionalized CNTs in the final composites. Another method is to have CNTs physically coated by some surfactants, which is a non-covalent approach and may be a more facile and practical processing technique. Gong et al. [63] added some surfactants in CNT/ epoxy composites to assist the dispersion of CNTs. Experimental results showed that CNTs were dispersed more evenly with the aid of the surfactant, and the elastic modulus of the composites was increased by more than $30 \%$. Nevertheless, CNTs treated by different surfactants may decrease the contact between CNTs, and thereby reduce the conductive properties of CNT/polymer composites.

In recent years, an interesting and successful noncovalent measure to obtain well-dispersed CNT/ polymer composites was developed by establishing ' $\pi$-cation'. Bellayer et al. [123] prepared well-dispersed MWNT/PS composites by melt extrusion, using trialkylimidazolium tetrafluoroborate-compatibilized MWNTs. Evidence for a ' $\pi$-cation' interaction between the CNT and imidazolium was found. In addition, the use of imidazolium salts in controlling the dispersion of SWNT was also reported [124]. Kodgire et al. [95] prepared for the first time CNT/PA6 composites through specific interactions between Na-AHA, which assisted debundling the MWNT and leading to homogeneous dispersion within matrix during melt-mixing. The composite fabricated by this route exhibited low electrical percolation threshold of $0.5 \mathrm{wt} \%$ at room temperature, the lowest reported value in this system so far. Reactive coupling was found to be a dominant factor besides ' $\pi$-cation' interaction in achieving low electrical percolation in MWNT/ PA6 composites.

It is worthy to mention the other efforts of synthesizing hybrid multi-scale reinforcement such as CNTs on carbon fibers [125-131] or on different ceramic particles [132]. In this case, CNTs can be homogeneously dispersed at microscale in the matrix with the help of these microscale carbon fibers or ceramic 'vehicle' because the microscale reinforcements can be much easily handled [132].

\subsection{Interfacial interaction between CNTs and polymer matrix}

Achieving suitable CNT-matrix interfacial bonding that provides effective stress transfer is another critical challenge for fabrication of CNT based polymer composites, especially for $\mathrm{CNT} /$ polymer structural composites. There are three main possible mechanisms of load transfer from a matrix to a reinforcement. The first is the weak van der Waals bonding between the reinforcement and the matrix, which is the main load transfer mechanism for $\mathrm{CNT} /$ polymer composites. In this case, interfacial energies normally amount to $\sim 50-350 \mathrm{~mJ} / \mathrm{m}^{2}$ [133]. The second is micromechanical interlocking, which can be marginal in CNT/polymer composites if the CNTs have atomically smooth surface. The third is chemical bonding between CNTs and matrix, which is not guaranteed in many cases.

It is possible to enhance the load transfer from a matrix to a reinforcement by different treatments to improve the mechanical performance of the composite, based on the above three main mechanisms of load transfer. The van der Waals bonding can be increased by using small size reinforcement and close contact at the interface. From this point of view, individual SWNTs well dispersed in a matrix is helpful. In the case of the micromechanical interlocking between CNTs and the matrix's molecular chains, it seems that the ideal situation is that: CNTs are strong enough and inter-connected or long enough to block the movement of the polymer chains $[34,134]$. The contribution of this mechanism may reach saturation at a relatively low CNT content [134]. It is unclear at this stage whether or not this critical content depends on the CNT orientation in the matrix. The chemical bonding between CNTs and matrices can be enhanced or created by surface treatments such as controlled oxidization, surface functionalization and physical coating. The question is whether or not such surface modification induces damage to the mechanical properties of the CNTs. The surface modification of the oxidized MWNTs was achieved by refluxing MWNTs with multi-functional amines by Gojny et al. [19] The TEM images of functionalized CNTs in the epoxy resin showed that CNTs were completely covered by the matrix. Telescopic pull-outs showed 
the outermost layer, which was directly bonded to the matrix, remained in the matrix, while the innertubes bridged the crack. All these results substantiate the evidence of improved interaction between CNTs and matrix.

Molecular dynamic simulation results given by Frankland et al. [135] showed that chemical crosslinks between SWNTs and polymer matrix could increase the shear strength of the SWNT-polymer interface by over an order of magnitude in comparison to the weak nonbonded interactions. Wagner et al. [136] examined stress-induced fragmentation of MWNTs in a polymer matrix. From the estimated values of CNT axial normal stress and elastic modulus, they concluded that the interfacial shear strength of CNT/polymer composites was at the order of $500 \mathrm{MPa}$. Wagner also calculated the interfacial shear strength of SWNT/polymer composites using a traditional force balance approach modified for a hollow tube, and examined the effect by varying some of the model parameters [137]. It was shown that high values of the interfacial shear strength (compared to those in current advanced fiber based polymer composites) were attainable. Cooper et al. [138] quantified the interfacial interaction between CNTs and epoxy matrix by detaching individual SWNT bundles and MWNTs from the epoxy matrix using a scanning probe microscope tip. The values for the interfacial shear strength were determined varying from 35 to $376 \mathrm{MPa}$. These results from both experimental measurements and theoretical simulations show that high values (up to several hundreds of $\mathrm{MPa}$ under certain conditions) of the interfacial interaction between CNTs and polymer matrices are in principle attainable.

\subsection{Contacts between individual CNTs}

As mentioned in sections 4.2 and 4.3 , surface treatment generally is used to improve CNT dispersion within the matrix and interfacial interaction between CNTs and matrix and it is very efficient to enhance the mechanical properties of the composite. However, surface treatment is adverse to a $\mathrm{CNT} /$ polymer functional composite in many cases. As we know, surface functionalization may disrupt the bonding between graphene sheets, and thereby reduce the intrinsic properties of CNTs in the final composites. Also, CNTs treated by different surfactants may decrease the contact between CNTs, and thereby reduce the final conductive properties of $\mathrm{CNT}$ /polymer composites. In fact, for a CNT/polymer functional composite, especially for an electric conducting composite, the effective conducting CNT path is primary, and good contact between individual CNTs is more important. An existing CNT conducting path does not guarantee good conductivity if the contact resistance between the individual CNTs is too high. Only when excellent electrical or thermal contact is established between the individual CNTs, the good electrical, thermal, wave or some other signals can be well transmitted. Several main factors may influence the contact resistance between CNTs, which finally determines the transport properties of CNT conducting path. The first is the intrinsic transport properties of CNTs, surface treatment for CNTs, therefore, is not desirable. The second is the orientation of CNTs within the matrix and the way that one CNT contacts with the others, overlap, end to end, one to one or one to more. The third is an insulating layer coating around $\mathrm{CNT}$ as well as its possible thickness, which is determined by the type of CNTs or polymers, the surface treatment of CNTs, and the processing method of the composites. Based on these analyses, it is possible to decrease the contact resistivity and improve the transport properties between individual CNTs by some measures. At first, high temperature treatment for CNTs to improve their intrinsic transport properties through improving their structural integrity and reducing the functional groups on their surface is preferable. To design and construct the contact means between CNTs by adjusting the content and orientation of CNTs within a matrix is also an effective measure. For example, to avoid the effect of contact resistance caused by the overlaps of CNTs in CNT passage, Huang et al. [113] proposed an ideal CNT composite structure, in which all the CNTs embedded in the matrix are aligned form one surface to the opposite side with all the CNT tips revealed on both surfaces. Another method is to weaken interfacial interaction between CNTs and matrix in order to decrease the interfacial interaction and then the quantity and quality of the polymer coating around CNTs during the processing of the composites $[112,139]$. From this view of point, CNT/polymer functional composites may be applied in practice before $\mathrm{CNT} /$ polymer structural composites since it is very difficult to improve interfacial interaction between CNTs and matrix but do not damage the 
intrinsic structure and the mechanical properties of CNTs.

\subsection{Other problems}

Besides above discussions, a few other problems exist for applied research of CNT/polymer composites. For instance, it is important to avoid interlayer slippage within MWNTs and slippage within SWNT bundles in order to fully take advantage of extra-high mechanical properties of CNTs in composites. Because interlayer slippage is an inherent structural property of MWNTs, no effective method has been found to solve this problem. This becomes even more critical when the outer layers of MWNTs are discontinuous. We know that no interlayer slippage can occur in SWNTs because they only have one shell. However, the slippage within SWNT bundles can also decrease the performance of CNT/polymer composites. Thus, isolation of individual SWNTs may be highly desirable. However, the binding energy of SWNTs in a bundle is high enough so that separation of SWNTs by polymer infiltration in the melt seems unlikely, unless some external force, such as that from ultrasonication for example, is utilized. In addition, the good CNT orientation gives rise to CNT/polymer composites with higher electrical conductivity and mechanical reinforcement, control of the alignment of CNTs towards the pre-determined direction, therefore, becomes another important issue for the design of these composites.

\section{Conclusions}

This article reviewed the present status of $\mathrm{CNT} /$ polymer composites. Based on the results reported up to now, CNTs are promising for fabricating both structural and functional composites which can be widely used in various important fields. However, it is obvious that the potential as reinforcing fillers in polymers especially for CNT/polymer structural composites have not been fully brought into play. The state-of-art indicates that great efforts should be continuously made before widely employing these advanced composites into practical usage. The critical challenges lie in how to prepare structure-controllable CNTs with high purity, geometrical identity and consistently dependable high performance, how to break up CNT products to obtain isolated CNTs, how to fab-

ricate composites with uniformly dispersed CNTs, and then how to enhance load transfer from a matrix to CNT reinforcement, etc. Scientists in different fields are worming their way to improve the status by innovative chemical techniques for CNT treatment and processing techniques for CNTs and CNT/polymer composites. Nevertheless, CNT/polymer composites present significant opportunities to basic science and nanotechnology, and pose significant challenges for future work in nanocomposite field.

\section{Acknowledgements}

This work was supported by the National Natural Science Foundation of China (No. 90606008) and by Chinese Academy Sciences. The support of the PICS (Programme International de Coopération Scientifique CNRS No. 3358, J. B. Bai \& H. M. Cheng) is also acknowledged. The authors sincerely thank Dr. Xiu-Juan He, Xin Tong, Zhe Ying, You Zeng and Shuo Bai for their valuable discussions.

\section{Glossary of abbreviation and symbols used in this article}

$\mathrm{CB}$

CNT

CP-NT

SWNT

MWNT

$\mathrm{CNF}$

PA6

PA12

PANI

PE

HDPE

UHMWPE

PEO

PET

PI

PMMA

PmPV

P3OT

$\mathrm{PP}$

PPA-C16TAB

PS carbon black carbon nanotube conducting polymer-carbon nanotube single-walled carbon nanotube multi-walled carbon nanotube carbon nanofiber

polyamide-6

polyamide- 12

polyaniline

polyethylene

high density polyethylene

Ultrahigh molecular weight polyethylene poly(ethylene oxide) poly(ethylene terephthalate) Polyimide poly(methyl methacrylate) poly(m-phenylenevinylene-co2,5-dioctoxy-p-phenylenevinylene) poly(3-octylthiophene) polypropylene poly(acrylic acid)-hexadecyltrimethy-ammonium bromide polystyrene 


$\begin{array}{ll}\text { PVA } & \text { poly(vinyl alcohol) } \\ \text { PVC } & \text { polyvinyl chloride } \\ \text { PVDF } & \text { poly(vinylidene fluoride) } \\ \text { SPAN } & \text { sulfonated polyaniline } \\ \text { TPU } & \text { Thermoplastic polyurethane } \\ \text { AIBN } & 2,2 \text { '-azobisisobutyronitrile } \\ \text { Na-AHA } & \text { sodium salt of 6-aminohexanoic } \\ & \text { acid }\end{array}$

$\begin{array}{ll}\text { EMI } & \text { electromagnetic interference } \\ \text { ESD } & \text { electrostatic dissipation } \\ \text { NTC } & \text { negative temperature coefficient } \\ \text { PTC } & \text { positive temperature coefficient } \\ \text { TIM } & \text { thermal interface material }\end{array}$

$K \quad$ thermal conductivity

$T_{g} \quad$ glass transition temperature

$T_{m} \quad$ melting temperature

LBL layer-by-layer

\section{References}

[1] Iijima S.: Heical microtubules of graphitic carbon. Nature, 354, 56-58 (1991).

[2] Robertson D. H., Brenner D. W., Mintmire J. W.: Energetics of nanoscale graphitic tubules. Physical Review: B, 45, 12592-12595 (1992).

[3] Yakobson B. I., Brabec C. J., Bernholc J.: Nanomechanics of carbon tubes: instabilities beyond linear response. Physical Review Letters, 76, 2511-2514 (1996).

[4] Lu J. P.: Elastic properties of carbon nanotubes and nanoropes. Physical Review Letters, 79, 1297-1300 (1997).

[5] Wong E. W., Sheehan P. E., Lieber C. M.: Nanobeam mechanics: elasticity, strength, and toughness of nanorods and nanotubes. Science, 277, 1971-1975 (1997).

[6] Cornwell C. F., Wille L. T.: Elastic properties of single-walled carbon nanotubes in compression. Solid State Communications, 101, 555-558 (1997).

[7] Kim P., Shi L., Majumdar A., McEuen P. L.: Thermal transport measurements of individual multiwalled nanotubes. Physical Review Letters, 87, 215502 (2001).

[8] Collins P. G., Avouris P.: Nanotubes for electronics. Scientific American, 283, 62-69 (2000).

[9] Weidenkaff A., Ebbinghaus S. G., Mauron P., Reller A., Zhang Y., Zuttel A.: Metal nanoparticles for the production of carbon nanotube composite materials by decomposition of different carbon sources. Materials Science and Engineering: C-Biomimetic and Supramolecular Systems, 19, 119-123 (2002).
[10] Chen W. X., Tu J. P., Wang L. Y., Gan H. Y., Xu Z. D., Zhang X. B.: Tribological application of carbon nanotubes in a metal-based composite coating and composites. Carbon, 41, 215-222 (2003).

[11] Tu J. P., Yang Y. Z., Wang L. Y., Ma X. C., Zhang X. B.: Tribological properties of carbon nanotube reinforced copper composites. Tribology Letters, 10, 225-228 (2001).

[12] Dong S. R., Tu J. P., Zhang X. B.: An investigation of the sliding wear behavior of $\mathrm{Cu}$-matrix composite reinforced by carbon nanotubes. Materials Science and Engineering: A, 313, 83-87 (2001).

[13] An J. W., Lim D. S.: Synthesis and characterization of alumina/carbon nanotube composite powders. Journal of Ceramic Processing Research, 3, 174-177 (2002).

[14] Zhao L. P., Gao L.: Novel in situ synthesis of MWNTs-hydroxyapatite composites. Carbon, 42, 423-426 (2004).

[15] Xia Z., Riester L., Curtin W. A., Li H., Sheldon B. W., Liang J., Chang B., Xu J. M.: Direct observation of toughening mechanisms in carbon nanotube ceramic matrix composites. Acta Materialia, 52, 931-944 (2004).

[16] Rul S., Lefevre-Schlick F., Capria E., Laurent C., Peigney A.: Percolation of single-walled carbon nanotubes in ceramic matrix nanocomposites. Acta Materialia, 52, 1061-1067 (2004).

[17] Sandler J., Shaffer M. S. P., Prasse T., Bauhofer W., Schulte K., Windle A. H.: Development of a dispersion process for carbon nanotubes in an epoxy matrix and the resulting electrical properties. Polymer, 40, 5967-5971 (1999).

[18] Schadler L. S., Giannaris S. C., Ajayan P. M.: Load transfer in carbon nanotube epoxy composites. Applied Physics Letters, 73, 3842-3844 (1998).

[19] Gojny F. H., Nastalczyk J., Roslaniec Z., Schulte K.: Surface modified multi-walled carbon nanotubes in CNT/epoxy-composites. Chemical Physics Letters, 370, 820-824 (2003).

[20] Jia Z. J., Wang Z., Xu C., Liang J., Wei B. Q., Wu D., Zhu S.: Study on poly(methyl methacrylate)/carbon nanotube composites. Materials Science and Engineering: A, 271, 395-400 (1999).

[21] De le Chapelle M. L., Stéphan C., Nguyen T. P., Lefrant S., Journet C., Bernier P., Munoz E., Benito A., Maser W. K., Martinez M. T., de la Fuente G. F., Guillard T., Flamant G., Alvarez L., Laplaze D.: Raman characterization of single-walled carbon nanotubes-PMMA composites. Synthetic Metals, 103, 2510-2512 (1999).

[22] Haggenmueller R., Gommans H. H., Rinzler A. G., Fischer J. E., Winey K. I.: Aligned single-wall carbon nanotubes in composites by melt processing methods. Chemical Physics Letters, 330, 219-225 (2000).

[23] Shaffer M. S. P., Windle A. H.: Fabrication and characterization of carbon nanotubes/poly(vinyl alcohol) composites. Advanced Materials, 11, 937-941 (1999). 
[24] Li F., Cheng H. M., Bai S., Su G., Dresselhaus M. S.: Tensile strength of single-walled carbon nanotubes directly measured from their macroscopic ropes. Applied Physical Letters, 77, 3161-3163 (2000).

[25] Dalton A. B., Collins S., Munoz E., Razal J. M., Ebron V. H., Ferraris J. P., Coleman J. N., Kim B. G., Baughman R. H.: Super-tough carbon-nanotube fibres. Nature, 423, 703 (2003).

[26] Kumar S., Doshi H., Srinivasarao M., Park J. O., Schiraldi D. A.: Fiber from polypropylene/nano carbon fiber composites. Polymer, 43, 1701-1703 (2002).

[27] Valentini L., Biagiotti J., Kenny J.M., Santucci S.: Morphological characterization of single-walled carbon nanotubes-PP composites. Composites Science and Technology, 63, 1149-1153 (2003).

[28] Tibbetts G. G., McHugh J. J.: Mechanical properties of vapor-grown carbon fiber composites with thermoplastic matrices. Journal of Materials Research, 14, 2871-2880 (1999).

[29] Tong X., Liu C., Cheng H. M., Zhao H. C., Yang F., Zhang X. Q.: Surface modification of single-walled carbon nanotubes with polyethylene via in situ Ziegler-Natta polymerization. Journal of Applied Polymer Science, 92, 3697-3700 (2004).

[30] Lozano K., Yang S. Y., Jones R. E.: Nanofiber toughened polyethylene composites. Carbon, 42, 2329_ 2331 (2004).

[31] Sandler J. K. W., Pegel S., Cadek M., Gojny F., van Es M., Lohmar J., Blau W. J., Schulte K., Windle A. H., Shaffer M. S. P.: A comparative study of melt spun polyamide-12 fibres reinforced with carbon nanotubes and nanofibres. Polymer, 45, 2001-2015 (2004).

[32] Hill D. E., Lin Y., Rao A. M., Allard L. F., Sun Y. P.: Functionalization of carbon nanotubes with polystyrene. Macromolecules, 35, 9466-9471 (2002).

[33] Liao K., Seam L. I.: Interfacial characteristic of a carbon nanotubes-polystyrene composite system. Applied Physics Letters, 79, 4225-4227 (2001).

[34] Bai J. B., Allaoui A.: Effect of the length and the aggregate size of MWNTs on the improvement efficiency of the mechanical and electrical properties. Compsites: Part A, 34, 689-694 (2003).

[35] Cadek M., Coleman J. N., Barron V., Hedicke K., Blau W. J.: Morphological and mechanical properties of carbon-nanotube-reinforced semicrystalline and amorphous polymer composites. Applied Physics Letters, 81, 5123-5125 (2002).

[36] Cooper C. A., Ravich D., Lips D., Mayer J., Wagner H. D.: Distribution and alignment of carbon nanotubes and nanofibrils in a polymer matrix. Composites Science and Technology, 62, 1105-1112 (2002).

[37] Xu X. J., Thwe M. M., Shearwood C., Liao K.: Mechanical properties and interfacial characteristics of carbon-nanotube-reinforced epoxy thin films. Applied Physics Letters, 81, 2833-2835 (2002).
[38] Lau K. T., Shi S. Q., Cheng H. M.: Micro-mechanical properties and morphological observation on fracture surfaces of carbon nanotube composites pre-treated at different temperatures. Composites Science and Technology, 63, 1161-1164 (2003).

[39] Mamedov A. A., Kotov N., Prato M., Guldi D. M., Wicksted J. P., Hirsch A.: Molecular design of strong single-wall carbon nanotube/polyelectrolyte multiplayer composites. Nature Materials, 1, 190-194 (2002).

[40] Carneiro O. S., Maia J. M.: Rheological behavior of (short) carbon fiber/thermoplastic composites. Part I: The Influence of fiber type, processing conditions and level of incorporation, Polymer Composites, 21, 960-969 (2000).

[41] Shaffer M. S. P., Sandler J. K. W.: Carbon nanotube/ nanofibre polymer composites. in 'Processing and properties of nanocomposites' (ed.: Advani S. G.) World Scientific, New York, 1-60, (2006).

[42] Jin Z. X., Pramoda K. P., Xu G. Q., Goh S. H.: Dynamic mechanical behavior of melt-processed multi-walled carbon nanotube/poly(methyl methacrylate) composites. Chemical Physics Letters, 337, 43-47 (2001).

[43] Du J. H., Ying Z., Bai S., Li F., Sun C., Cheng H. M.: Microstructure and resistivity of carbon nanotube and nanofiber/epoxy matrix nanocomposites. International Journal of Nanoscience, 1, 719-723 (2002).

[44] Ying Z., Du J. H., Bai S., Li F., Liu C., Cheng H. M.: Mechanical properties of surfactant-coating carbon nanofiber/epoxy composite. International Journal of Nanoscience, 1, 425-430 (2002).

[45] Du J. H.: Electromagnetic properties and microwave absorption characteristics of fibrous nano-carbon materials and their composites. PhD Thesis, Institute of Metal Research, Chinese Academy of Sciences, Shenyang, (2003).

[46] Li X. H., Wu B., Huang J., Zhang J., Liu Z. F., Li H. L.: Fabrication and characterization of well-dispersed single-walled carbon nanotube/polyaniline composites. Carbon, 41, 1670-1673 (2002).

[47] Feng W., Bai X. D., Lian Y. Q., Liang J., Wang X. G., Yoshino K.: Well-aligned polyaniline/carbon-nanotube composite films grown by in-situ aniline polymerization. Carbon, 41, 1551-1557 (2003).

[48] Andrew R., Jacques D., Rao A. M., Rantell T., Derbyshire F., Chen Y., Chen J., Haddon R. C.: Nanotube composite carbon fibers. Applied Physics Letters, 75, 1329-1331 (1999).

[49] Vigolo B., Pénicaud A., Coulon C., Sauder C., Pailler R., Journet C., Bernier P., Poulin P.: Macroscopic fibers and ribbons of oriented carbon nanotubes. Science, 290, 1331-1334 (2000).

[50] Bhattacharyya A. R., Sreekumar T. V., Liu T., Kumar S., Ericson L. M., Hauge R. H., Smalley R. E.: Crystallization and orientation studies in polypropylene/ single wall carbon nanotube composite. Polymer, 44, 2373-2377 (2003). 
[51] Ajayan P. M., Stephan O., Colliex C., Trauth D.: Aligned carbon nanotube arrays formed by cutting a polymer resin-nanotube composite. Science, 265, 1212-1214 (1994).

[52] Jin L., Bower C., Zhou O.: Alignment of carbon nanotubes in a polymer matrix by mechanical stretching. Applied Physics Letters, 73, 1197-1199 (1998).

[53] Bower C., Rosen R., Jin L., Han J., Zhou O.: Deformation of carbon nanotubes in nanotube-polymer composites. Applied Physics Letters, 74, 3317-3319 (1999).

[54] Kimura T., Ago H., Tobita M., Ohshima S., Kyotani M., Yumura M.: Polymer composites of carbon nanotubes aligned by a magnetic field. Advanced Materials, 14, 1380-1383 (2002).

[55] Sen R., Zhao B., Perea D., Itkis M. E., Hu H., Love J., Bekyarova E., Haddon R. C.: Preparation of singlewalled carbon nanotube reinforced polystyrene and polyurethane nanofibers and membranes by electrospinning. Nano Letters, 4, 459-464 (2004).

[56] Gao M., Huang S., Dai L., Wallace G., Gao R., Wang Z. L.: Aligned coaxial nanowires of carbon nanotubes sheathed with conducting polymers. Angewandte Chemie, 39, 3664-3667 (2000).

[57] Shofner M. L., Rodríguez-Macías F. J., Vaidyanathan R., Barrera E. V.: Single wall nanotube and vapor grown carbon fiber reinforced polymers processed by extrusion freeform fabrication. Composites: Part A, 34, 1207-1217 (2003).

[58] Coleman J. N., Khan U., Blau W. J., Gun'ko Y. K.: Small but strong: A review of the mechanical properties of carbon nanotube-polymer composites. Carbon, 44, 1624-1652 (2006).

[59] Baughman R. H., Zakhidov A. A., de Heer W. A.: Carbon nanotubes-the route toward applications. Science, 297, 787-792 (2002).

[60] Lau K. T., Hui D.: Effectiveness of using carbon nanotubes as nano-reinforcements for advanced composite structures. Carbon, 40, 1605-1606 (2002).

[61] Lau K. T.: Interfacial bonding characteristics of nanotube/polymer composites. Chemical Physics Letters, 370, 399-405 (2003).

[62] Calvert P.: A recipe for strength. Nature, 339, 210211 (1999).

[63] Davey A. P., Coleman J., Dalton A., Maier S., Drury A., Gray D., Brennan M., Ryder K., Lamy De La Chapelle M., Journet C., Bernier P., Carroll D., Blau W., Byrne H. J., Ajayan P. M., Lefrant S.: Evolution and evaluation of the polymer/nanotube composite. Synthetic Metals, 103, 2559-2562 (1999).

[64] Ajayan P. M., Schandler L. S., Gianaris C., Rubio A.: Single-walled carbon nanotube-polymer composites: strength and weakness. Advanced Materials, 12, 750753 (2000).

[65] Gong X. Y., Liu J., Baskaran S., Voise R. D., Young J. S.: Surfactant-assisted processing of carbon nanotube/polymer composites. Chemistry of Materials, 12, 1049-1052 (2000).
[66] Andrews R., Jacques D., Minot M., Rantell T.: Fabrication of carbon multiwall nanotube/polymer composites by shear mixing. Macromolecular Materials and Engineering, 287, 395-403 (2002).

[67] Zhang Q., Rastogi S., Chen D., Lippits D., Lemstra P. J.: Low percolation threshold in single-walled carbon nanotube/high density polyethylene composites prepared by melt processing technique. Carbon, 44, 778785 (2006).

[68] Qian D., Dickey E. C., Andrews R., Rantell T.: Load transfer and deformation mechanisms in carbon nanotube-polystyrene composites. Applied Physics Letters, 76, 2868-2870 (2000).

[69] Jin Z. X., Pramoda K. P., Goh S. H., Xu G. Q.: Poly(vinylidene fluoride)-assisted melt-blending of multi-walled carbon nanotube/poly(methyl methacrylate) composite. Materials Research Bulletin, 37, 271278 (2002).

[70] Geng H. Z., Rosen R., Zheng B., Shimoda H., Fleming L., Liu J., Zhou O.: Fabrication and properties of composites of poly(ethylene oxide) and functionalized carbon nanotubes. Advanced Materials, 14, 1387-1390 (2002).

[71] Paiva M. C., Zhou B., Fernando K. A. S., Lin Y., Kennedy J. M., Sun Y. P., Mechanical and morphological characterization of polymer-carbon nanocomposites from functionalized carbon nanotubes. Carbon, 42, 2849-2854 (2004).

[72] Siochi E. J., Working D. C., Park C., Lillehei P. T., Rouse J. H., Topping C. C., Bhattacharyya A. R., Kumar S.: Melt processing of SWCNT-polyimide nanocomposite fibers. Composites: Part B, 35, 439446 (2004).

[73] Chen W., Tao X. M.: Production and characterization of polymer nanocomposite with aligned single wall carbon nanotubes. Applied Surface Science, 252, 3547-3552 (2006).

[74] Ruan S., Gao P., Yu T. X.: Ultra-strong gel-spun UHMWPE fibers reinforced using multiwalled carbon nanotubes. Polymer, 47, 1604-1611 (2006).

[75] Meguid S. A., Sun Y.: On the tensile and shear strength of nano-reinforced composite interfaces. Materials and Design, 25, 289-296 (2004).

[76] Shaffer M., Kinloch I. A.: Prospects for nanotube and nanofiber composites. Composites Science and Technology, 64, 2281-2282 (2004).

[77] Ruan S. L., Gao P., Yang X. G., Yu T. X.: Toughening high performance ultrahigh molecular weight polyethylene using multiwalled carbnon nanotubes. Polymer, 44, 5643-5654 (2003).

[78] Andrews R., Weisenberger M. C.: Carbon nanotube polymer composites. Current Opinion in Solid State \& Materials Science , 8, 31-37 (2004).

[79] Vollrath F. Knight D. P.: Liquid crystalline spinning of spider silk. Nature, 410, 541-548 (2001).

[80] Ogando J.: Nanotech goes to bat: Carbon nanotubes boost bat performance. Design News, Issue 8: The sport page, June 5 (2006). 
[81] Martin C. A., Sandler J. K. W., Shaffer M. S. P., Schwarz M. K., Bauhofer W., Schulte K., Windle A. H.: Formation of percolating networks in multi-wall carbon-nanotube-epoxy composites. Composites Science and Technology, 64, 2309-2316 (2004).

[82] Zhu B. K., Xie S. H., Xu Z. K., Xu Y. Y.: Preparation and properties of the polyimide/multi-walled carbon nanotubes (MWNTs) nanocomposites. Composites Science and Technology, 66, 548-554 (2006).

[83] Sandler J. K. W., Kirk J. E., Kinloch I. A., Shaffer M. S. P., Windle A. H.: Ultra-low electrical percolation threshold in carbon-nanotube-epoxy composites. Polymer, 44, 5893-5899 (2003).

[84] Allaoui A., Bai S., Cheng H. M., Bai J. B.: Mechanical and electrical properties of a MWNT/epoxy composite. Composites Science and Technology, 62, 19931998 (2002).

[85] Dufresne A., Paillet M., Putaux J. L., Canet R., Carmona F., Delhaes P., Cui S.: Processing and characterization of carbon nanotube/poly(styrene-co-butyl acrylate) nanocomposites. Journal of Material Science, 37, 3915-3923 (2002).

[86] Barraza H. J., Pompeo F., O’Rear E. A., Resasco D. E.: SWNT-Filled Thermoplastic and Elastomeric Composites Prepared by Miniemulsion Polymerization. Nano Letters, 2, 797-802 (2002).

[87] McNally T., Pötschke P., Halley P., Murphy M., Martin D., Bell S. E. J., Brennan G. P., Bein D., Lemoine P., Quinn J. P: Polyethylene multiwalled carbon nanotube composites. Polymer, 46, 8222-8232 (2005).

[88] Hu G., Zhao C., Zhang S., Yang M., Wang Z.: Low percolation thresholds of electrical conductivity and rheology in poly(ethylene terephthalate) through the networks of multi-walled carbon nanotubes. Polymer, 47, 480-488 (2006).

[89] Seo M. K., Park S. J.: Electrical resistivity and rheological behaviors of carbon nanotubes-filled polypropylene composites. Chemical Physics Letters, 395, 44-48 (2004).

[90] Seo M. K., Lee J. R., Park S. J.: Crystallization kinetics and interfacial behaviors of polypropylene composites reinforced with multi-walled carbon nanotubes. Materials Science and Engineering: A, 404, 7984 (2005).

[91] Tchmutin I. A., Ponomarenko A. T., Krinichnaya E. P., Kozub G. I., Efimov O. N.: Electrical properties of composites based on conjugated polymers and conductive fillers. Carbon, 41, 1391-1395 (2003).

[92] Meincke O., Kaempfer D., Weickmann H., Friedrich C., Vathauer M., Warth H.: Mechanical properties and electrical conductivity of carbon-nanotube filled polyamide- 6 and its blends with acrylonitrile/butadiene/ styrene. Polymer, 45, 739-748 (2004).

[93] Coleman J. N., Curran S., Dalton A. B., Davey A. P., McCarthy B., Blau W., Barklie R. C.: Percolationdominated conductivity in a conjugated-polymer-carbon-nanotube composite. Physical Review B, 58, $7492-7495$ (1998).
[94] Kymakis E., Alexandou I., Amaratunga G. A. J.: Single-walled carbon nanotube-polymer composites: electrical, optical, and structural investigation. Synthetic Metals, 127, 59-62 (2002).

[95] Kodgire P. V., Bhattacharyya A. R., Bose S., Gupta N., Kulkarni A. R., Misra A.: Control of multiwall carbon nanotubes dispersion in polyamide 6 matrix: An assessment through electrical conductivity. Chemical Physics Letters, 432, 480-485 (2006).

[96] He X. J., Du J. H., Ying Z., Cheng H. M.: Positive temperature coefficient effect in multiwalled carbon nanotube/high-density polyethylene composites. Applied Physics Letters, 86, 062112/1-062112/3 (2005).

[97] Berber S., Kwon Y-K., Tománek D.: Unusually high thermal conductivity of carbon nanotubes. Physical Review Letters, 84, 4613-4616 (2000).

[98] Kim P., Shi L., Majumdar A., McEuen P. L.: Thermal transport measurements of individual multiwalled nanotubes. Physical Review Letters, 87, 215502-215505 (2000).

[99] Kashiwagi T., Grulke E., Hilding J., Harris R., Awad W., Douglas J. F.: Thermal degradation and flammability properties of poly(prorylene)/carbon nanotube composites. Macromolecular Rapid Communications, 23, 761-765 (2002).

[100] Du F. M., Fischer J. E., Winey K. I.: Coagulation method for preparing single-walled carbon nanotube/ poly(methyl methacrylate) composites and their modulus, electrical conductivity, and thermal stability. Journal of Polymer Science: Part B. Polymer Physics, 41, 3333-3338 (2003).

[101] Wei C. Y., Srivastava D., Cho K.: Thermal expansion and diffusion coefficients of carbon nanotubepolymer composites. Nano Letters, 2, 647-650 (2002).

[102] Biercuk M. J., Llaguno M. C., Radosavljevic M., Hyun J. K., Johnson A. T., Fischer J. E.: Carbon nanotube composites for thermal management. Applied Physics Letters, 80, 2767-2769 (2002).

[103] Xu Y. S., Ray G., Abdel-Magid B.: Thermal behavior of single-walled carbon nanotube polymer-matrix composites. Composites: Part A, 37, 114-121 (2006).

[104] Thostenson E., Chou T-W.: Processing-structuremulti-functional property relationship in carbon nanotube/epoxy composites. Carbon, 44, 3022-3029 (2006).

[105] Liu C. H., Huang H., Wu Y., Fan S. S.: Thermal conductivity improvement of silicone elastomer with carbon nanotube loading. Applied Physics Letters, 84, 4248-4250 (2004).

[106] Shenogin S., Xue L., Ozisik R., Keblinski P., Cahill D. G.: Role of thermal boundary resistance on the heat flow in carbon-nanotube composites. Journal of Applied Physics, 95, 8136-8144 (2004). 
[107] Huxtable S. T., Cahill D. G., Shenogin S., Xue L. P., Ozisik R., Barone P., Usrey M., Strano M. S., Siddons G., Shim M., Keblinski P.: Interfacial heat flow in carbon nanotube suspensions. Nature Materials, 2, 731-734 (2003).

[108] Nan C. W., Liu G., Lin Y., Li M.: Interface effect on thermal conductivity of carbon nanotube composites. Applied Physics Letters, 85, 3549-3551 (2004).

[109] Bagchi A., Nomura S.: On the effective thermal conductivity of carbon nanotube reinforced polymer composites. Composites Science and Technology, 66, 1703-1712 (2006).

[110] Shenogin S., Bodapati A., Xue L., Ozisik R., Keblinski P.: Effect of chemical functionalization on thermal transport of carbon nanotube composites. Applied Physics Letters, 85, 2229-2231 (2004).

[111] Liu C. H., Fan S. S.: Effects of chemical modifications on the thermal conductivity of carbon nanotube composites. Applied Physics Letters, 86, 123106/1123106/3 (2005).

[112] Gojny F. C., Wichmann M. H. G., Fiedler B., Kinloch I. A., Bauhofer W., Windle A. H., Schulte K.: Evaluation and identification of electrical and thermal conduction mechanisms in carbon nanotube/ epoxy composites. Polymer, 47, 2036-2045 (2006).

[113] Huang H., Liu C., Wu Y., Fan S. S.: Alighed carbon nanotube composite films for thermal management. Advanced Materials, 17, 1652-1656 (2005).

[114] Wu Y., Liu C.H., Huang H., Fan S. S.: Effects of surface metal layer on the thermal contact resistance of carbon nanotube arrays. Applied Physics Letters, 87, 213108/1-213108/3 (2005).

[115] Jin Z. X., Huang L., Goh S. H., Xu G. Q., Ji W.: Characterization and nonlinear optical properties of a poly(acryli acid)-surfactant-multi-walled carbon nanotube complex. Chemical Physics Letters, 322, 461-566 (2000).

[116] Jin Z. X., Sun X., Xu G., Goh S. H., Ji W.: Nonlinear optical properties of some polymer/multi-walled carbon nanotube composites. Chemical Physics Letters, 318, 505-510 (2000).

[117] Chen Y. C., Raravikar N. R., Schadler L. S., Ajayan P. M., Zhao Y. P., Lu T. M., Wang G. C., Zhang X. C.: Ultrafast optical switching properties of singlewall carbon nanotube polymer composites at $1.55 \mathrm{~m}$. Applied Physics Letters, 81, 975-977 (2002).

[118] Fan Z. J., Luo G. H., Zhang Z. F., Zhou L., Wei F.: Electromagnetic and microwave absorbing properties of multi-walled carbon nanotubes/polymer composites. Materials Science and Engineering: B, 132, 85-89 (2006).

[119] Wei Z. X., Wan M. X., Lin T., Dai L. M.: Polyaniline nanotubes doped with sulfonated carbon nanotubes made a self-assembly process. Advanced Materials, 15, 136-139 (2003).

[120] Zhang H., Li H. X., Cheng H. M.: Water-Soluble Multiwalled Carbon Nanotubes Functionalized with Sulfonated Polyaniline. The Journal of Physical Chemistry: B, 110, 9095-9099 (2006).
[121] Valentini L., Kenny J. M.: Novel approaches to developing carbon nanotube based polymer composites: fundamental studies and nanotech applications. Polymer, 46, 6715-6718 (2005).

[122] Thostenson E. T., Ren Z. F., Chou T. W.: Advances in the science and technology of carbon nanotubes and their composites: a review. Composites Science and Technology, 61, 1899-1912 (2001).

[123] Bellayer S., Gilman J. W., Eidelman N., Bourbigot S., Flambard X., Fox D. M., De Long H. C., Trulove P. C.: Preparation of homogeneously dispersed multiwalled carbon nanotube/polystyrene nanocomposites via melt extrusion using trialkyl imidazolium compatibilizer. Advanced Functional Materials, 15, 910-916 (2005).

[124] Fukushima T., Kosaka A., Ishimura Y., Yamamoto T., Takigawa T., Ishii N., Aida T.: Molecular ordering of organic molten salts triggered by singlewalled carbon nanotubes. Science, 300, 2072-2074 (2003).

[125] Otsuka K., Abe Y., Kanai N., Kobayashi Y., Takenaka S., Tanabe E.: Synthesis of carbon nanotubes on $\mathrm{Ni}$ /carbon-fiber catalysts under mild conditions. Carbon, 42, 727-736 (2004).

[126] Zhu S., Su C. H., Lehoczky S. L., Muntele I., Ila D.: Carbon nanotube growth on carbon fibers. Diamond and Related Materials, 12, 1825-1828 (2003).

[127] Wei B. Q., Vajtai R., Ajayan P. M.: Sequence growth of carbon fibers and nanotube networks by CVD process. Carbon, 41, 185-188 (2003).

[128] Smiljanic O., Dellero T., Serventi A., Lebrun G., Stansfield B. L., Dodelet J. P., Trudeau M., Désilets S.: Growth of carbon nanotubes on ohmically heated carbon paper. Chemical Physics Letters, 342, 503509 (2001).

[129] Thostenson E. T., Li W. Z., Wang D. Z., Ren Z. F., Chou T. W.: Carbon nanotube/carbon fiber hybrid multiscale composites. Journal of Applied Physics, 91, 6034-6037 (2002).

[130] Ci L. J., Zhao Z. G., Bai J. B.: Direct growth of aligned carbon nanotubes on the surface of ceramic fibers. Carbon, 43, 883-886 (2005).

[131] Zhao Z. G., Ci L. J., Cheng H. M., Bai J. B.: Growth of multi-walled carbon nanotube of different morphologies on carbon fibres by floating catalyst method. Carbon, 43, 663-665 (2004).

[132] Ci L. J. Bai J. B.: Novel micro/nanoscale hybrid reinforcement: multi-walled carbon nanotubes on $\mathrm{SiC}$ particles. Advanced Materials, 16, 2021-2024 (2004).

[133] Nardin M., Schultz J.: Effect of elastic-moduli and interfacial adhesion energy on the critical fiber aspect ratio in single-fiber composites. Journal of Materials Science Letters, 12, 1245-1247 (1993).

[134] Bai J. B.: Evidence of the reinforcement role of CVD multi-walled carbon nanotubes in a polymer matrix. Carbon, 41, 1331-1334 (2003). 
[135] Frankland S. J. V., Harik V. M.: Analysis of carbon nanotube pull-out from a polymer matrix. Surface Science, 525, 103-108 (2003).

[136] Wagner H. D., Lourie O., Feldman Y., Tenne R.: Stress-induced fragmentation of multiwall carbon nanotubes in a polymer matrix. Applied Physics Letters, 72, 188-190 (1998).

[137] Wagner H. D.: Nanotube-polymer adhesion: a mechanics approach. Chemical Physics Letters, 361, 57-61 (2002).

[138] Cooper C. A., Cohen S. R., Barber A. H., Wagner H. D.: Detachment of nanotubes from a polymer matrix. Applied Physics Letters, 81, 3873-3875 (2002).

[139] Zhang H.: PhD Thesis, Surface modification of carbon nanotubes and electrical properties of carbon nanotube composites. Institute of Metal Research, Chinese Academy of Sciences (2006).

\section{Appendix: list of published review papers related to $\mathrm{CNT} /$ polymer composites}

[A1] Gibson R. F., Ayorinde E. O., Wen Y. F.: Vibrations of carbon nanotubes and their composites: A review. Composite Science and Technology, 67, 1-28, (2007).

[A2] Coleman J. N., Khan U., Blau W. J., Gun'ko Y. K.: Small but strong: A review of the mechanical properties of carbon nanotube-polymer composites. Carbon, 44, 1624-1652 (2006).

[A3] Moniruzzaman M., Winey K. I.: Polymer nanocomposites containing carbon nanotubes. Macromolecules, 39, 5194-5205 (2006).

[A4] Lau K. T., Gu C., Hui D.: A critical review on nanotube and nanotube/nanoclay related polymer composite materials. Composites: Part B, 37, 425-436 (2006)

[A5] Coleman J. N., Khan U., Gun'ko Y. K.: Mechanical reinforcement of polymers using carbon nanotubes. Advanced Materials 18, 689-706 (2006).
[A6] Liu P.: Modifications of carbon nanotubes with polymers. European Polymer Journal, 41, 2693-2703 (2005).

[A7] Desai A. V., Haque M. A.: Mechanics of the interface for carbon nanotube-polymer composites. ThinWalled Structures, 43, 1787-1803 (2005).

[A8] Xie X. L., Mai Y. W. Zhou X. P.: Dispersion and alignment of carbon nanotubes in polymer matrix: A review. Materials Science and Engineering: $\mathrm{R}$ Reports, 49, 89-112 (2005).

[A9] Chae H. G., Sreekumar T. V., Uchida T., Kumar S.: A comparison of reinforcement efficiency of various types of carbon nanotubes in polyacrylonitrile fiber. Polymer, 46, 10925-10935 (2005).

[A10] Potschke P, Bhattacharyya A. R., Janke A., Goering H.: Composites of polycarbonate with multiwalled carbon nanotubes produced by melt mixing. ACS Symposium Series, 898, 148-163 (2005).

[A11] Velasco-Santos C., Martinez-Hernandez A. L., Castano V. M.: Carbon nanotube-polymer nanocomposites: The role of interfaces. Composite Interfaces, 11, 567-586 (2005)

[A12] Breuer O., Sundararaj U.: Big Returns From Small Fibers: A review of polymer/carbon nanotube composites. Polymer Composites, 25, 630-645 (2004).

[A13] Andrews R., Weisenberger M. C: Carbon nanotube polymer composites. Current Opinion in Solid State \& Materials Science, 8, 31-37 (2004).

[A14] Harris P. J. F.: Carbon nanotube composites. International Materials Reviews, 49, 31-43 (2004).

[A15] Li L. X., Li F., Ying Z., Yang Q. H., Cheng H. M.: Carbon nanotube/polymer functional composite. New Carbon Materials, 18, 69-74 (2003).

[A16] Baughman R. H., Zakhidov A. A., Heer W. A.: Carbon nanotubes-the route toward applications. Science, 297, 787-792 (2002).

[A17] Thostenson E. T., Ren Z., Chou T. W.: Advances in the science and technology of carbon nanotubes and their composites: a review. Composites Science and Technology, 61, 1899-1912 (2001). 